\title{
استراتيجيات التعلم المنظم ذاتيا لدى طلاب التعليم الإفتوح \\ في ضوء بعض المتغيرات الديموجرافية
}

إعداد

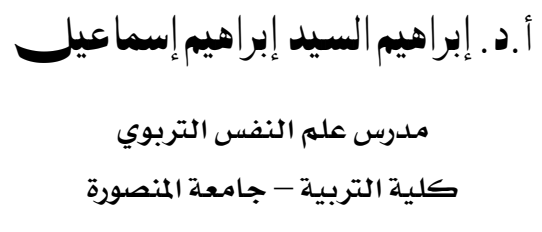

$$
\begin{aligned}
& \text { أ.ده . محمد عبد السميع رزق محمد }
\end{aligned}
$$

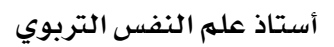

$$
\begin{aligned}
& \text { وكيل الكلية لشئون البيئة وخدمة المجتمع } \\
& \text { كلية التربية - جامعة المنصورة لبيدة }
\end{aligned}
$$

أ. يـارا محمد الدمرداش

$$
\text { باحثة ماجستير }
$$

مجلة بحوث التربية النوعية ـ جامعة المنصورة

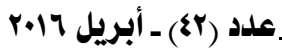




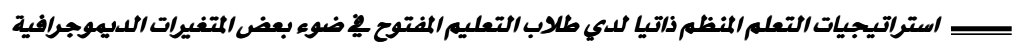




\title{
استزاتيجيات التعلم المنظم ذاتيا لدي طلاب التعليم المفتوح \\ في ضوى بعض المتغيرات الديموجرافية
}

\author{
إعداد \\ يارامحمد الدمرداش***

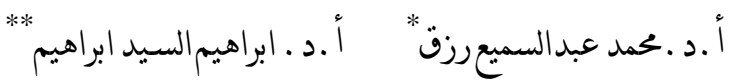

هلمص البحث

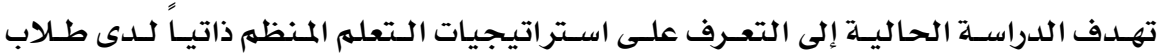

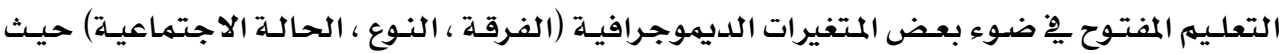

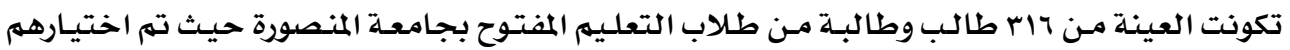

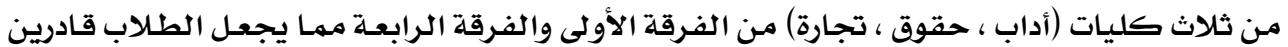

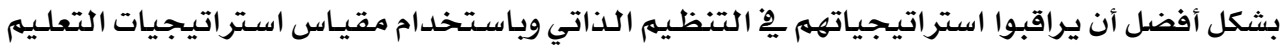

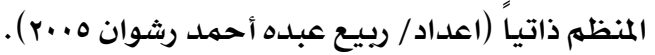

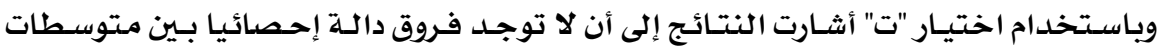

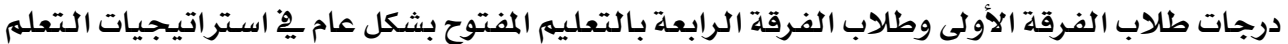
المنظم ذاتيا.

\section{هقدهة الدراسة:}

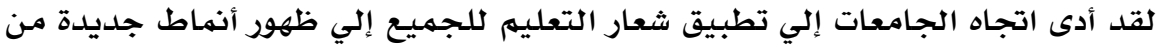

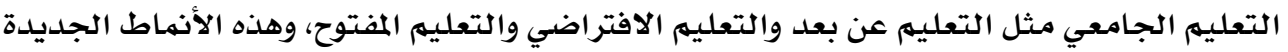

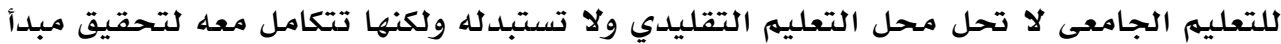

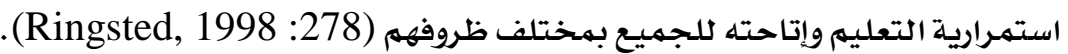
ويعد التعليم الجامعي المفتوح من أبرز مظاهر التجديد التربوي، لكونه أحد البدائل القادرة

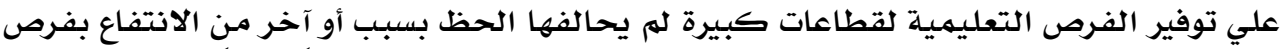

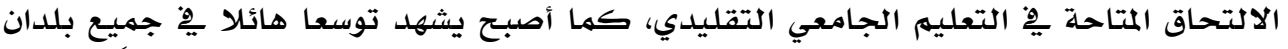

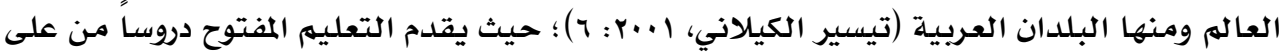

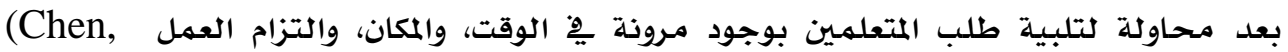

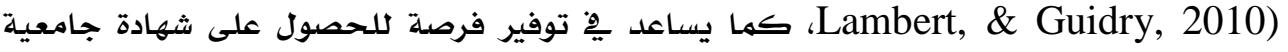

* أستاذ عله النفس التربوى وكيل الكلية لشئون البيئلة وخدمة المجتمع كلية التربية - جامعة المنصورة

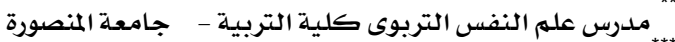


للمتعلمـين الذين له يتمكنوا من الحصول عليها، والحصول على المزيد من الدورات التدريبية .(Parsad \& Lewis, 2008)

والمحلل للتجارب العالمية يِّ مجال التعليم المفتوح وما أسفرت عنه توصيات المؤتمرات

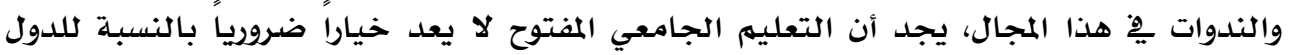

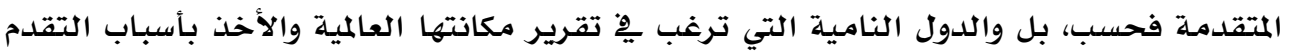

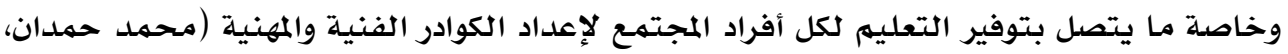
(rVq:r..)

وتعد مصر إحدى الدول التي خاضت تجرية التعليه المفتوح، من خلال إنشاء مراكز

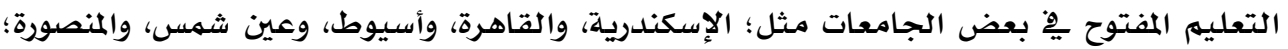

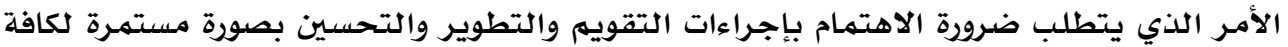

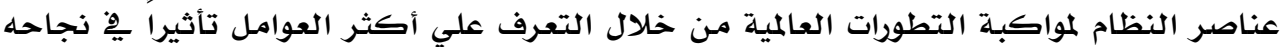

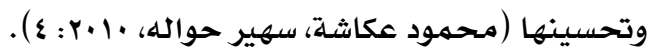
حيث نتج عن التطورات السريعة والمتلاحقة والهائلة يف شتي فروع المعرفة وتزايد الأعداد

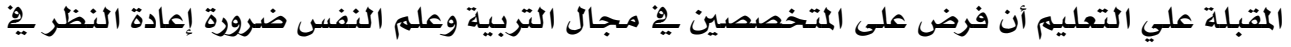

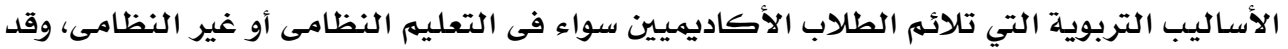

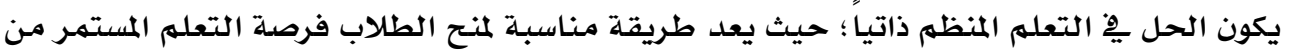
خلال زيادة الاستقلالية والنشاط للمتعلهم (Bandura, 2000).

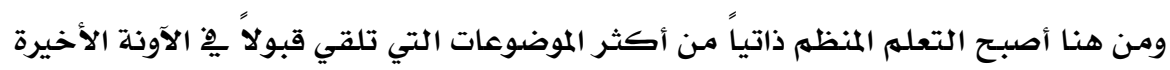

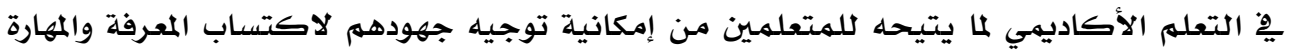

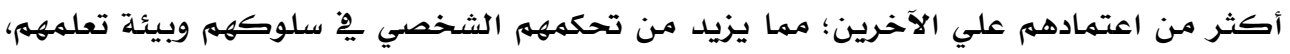

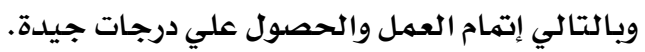

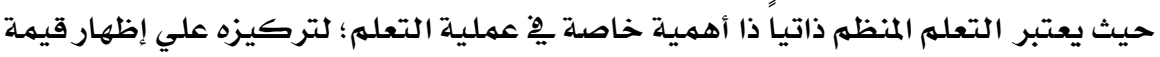

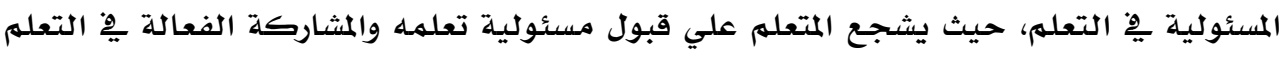

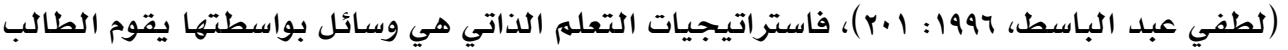

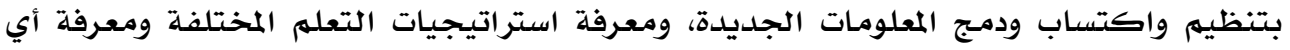

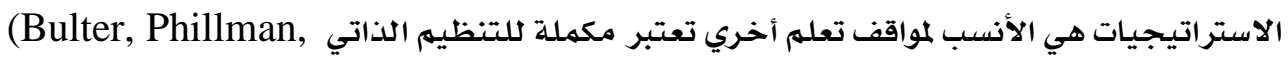
\& Smart, 2001)

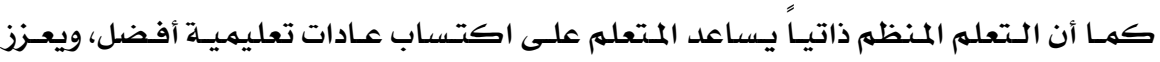

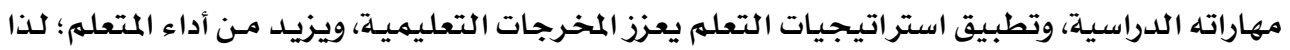

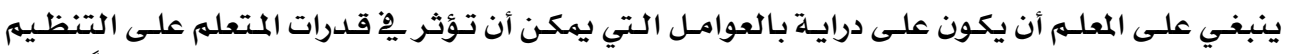

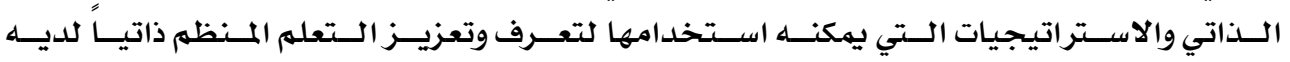
.(Zumbrunn, Tadlock, \& Roberts, 2011, 4) 
ويشير تشنج (Cheng, 2011, 5) إلى أن المتعلهم المنظم ذاتياً يمكن أن ينظم اسـتراتيجياته

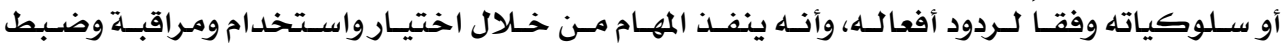

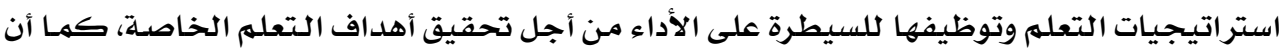

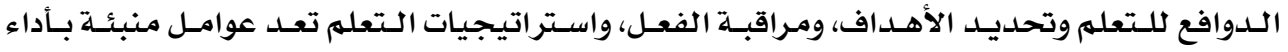

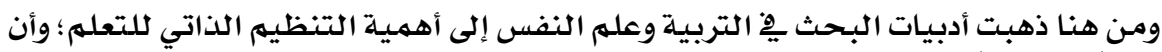

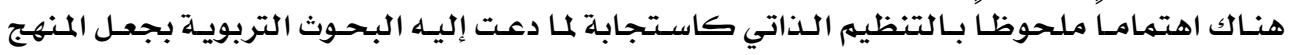

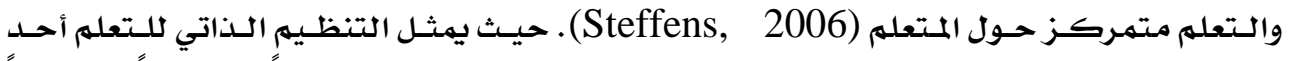

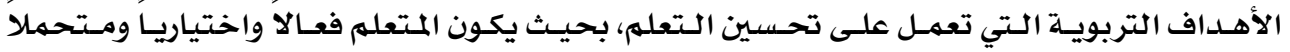
مسئولية تعلمها (Vrugt \& Oort, 2008). وكذلك يِّ ضـوء مـا ذهب إليه سـامس، وفريدل (Samms \& Friedel, 2012) مـن أن

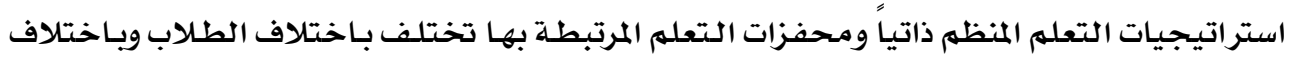

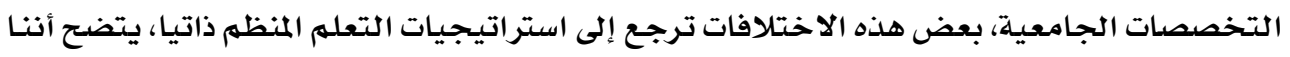

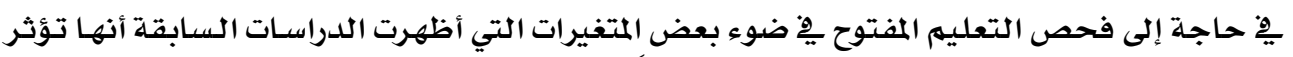
مِّْ متغير الدراسة (استراتيجيات التعلهم المنظم ذاتياً ). هشكالة الدراستة:

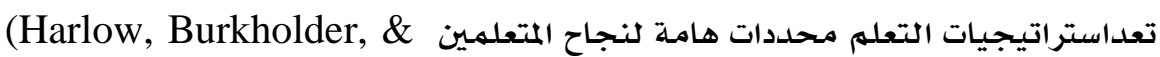

Morrow, 2002; Jacobson \& Harris 2008; Paulsen \& Gentry, 1995; Quible, (Wang أ2006; Wang, Peng, Huang, Hou, \& Wang, 2008) الابحابد et al., 2008) الإيجابية للطلاب. ويشير كويبل (Quible, 2006) إلى أن استراتيجيات التعله للتعلم يؤثران

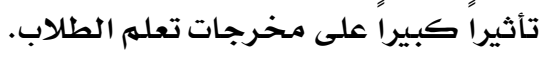

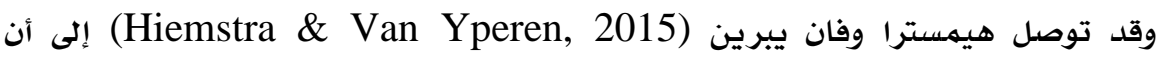

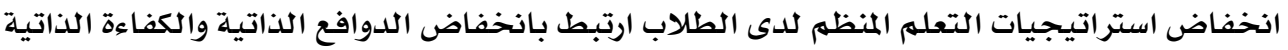

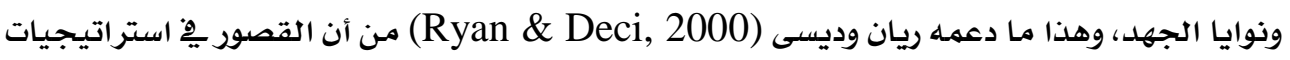

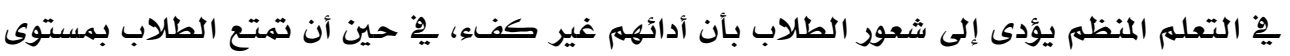

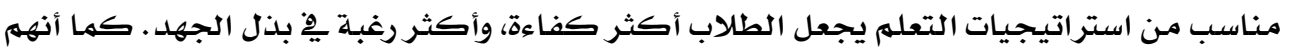

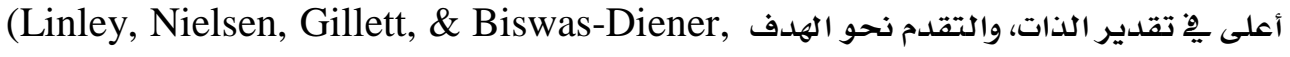

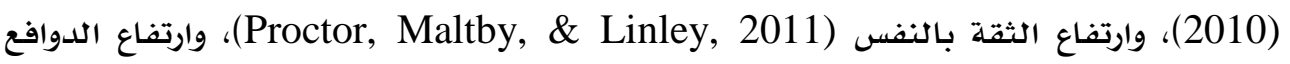
الاكاديمية الذاتية (2005)، وارتفاع الثقة بالنفي

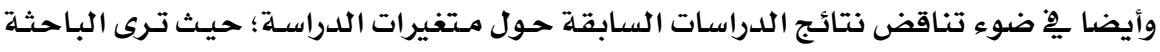

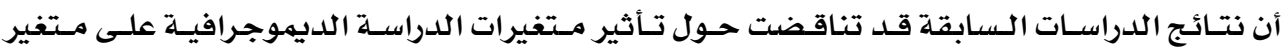




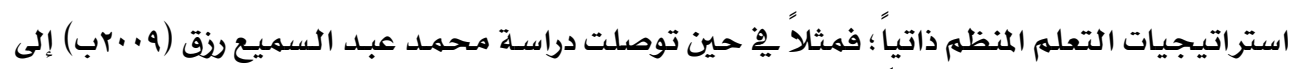

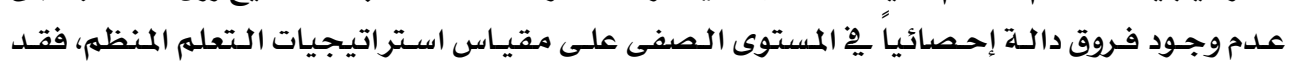

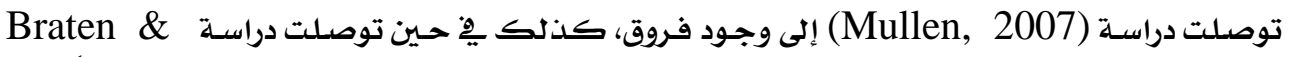
(Stroso, 2005)

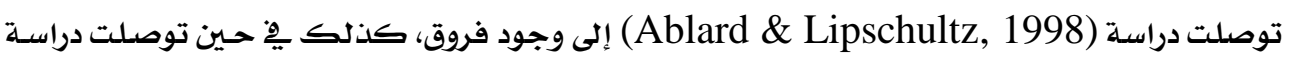

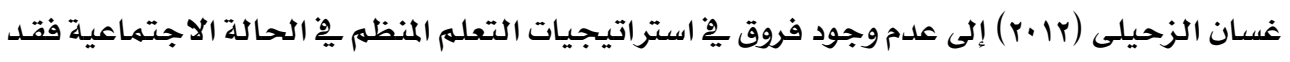

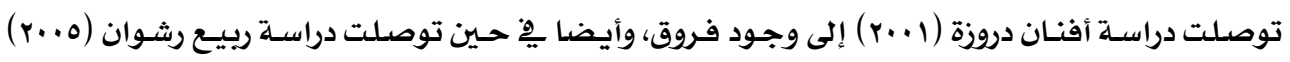

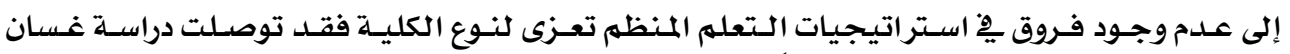

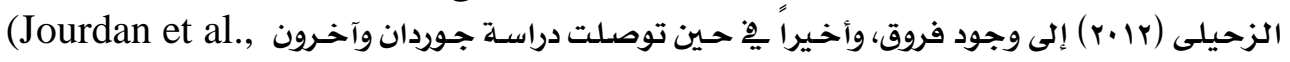

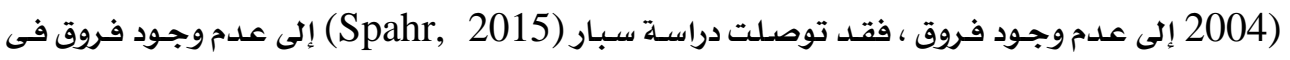

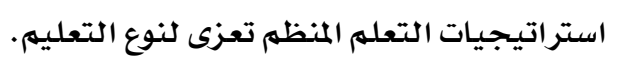

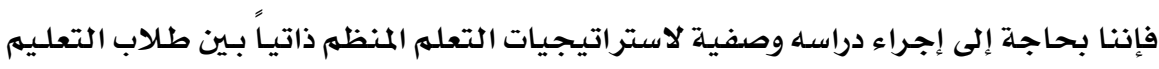

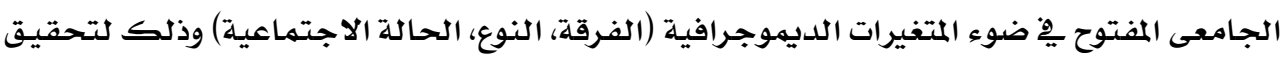

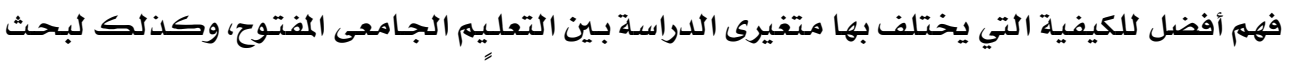

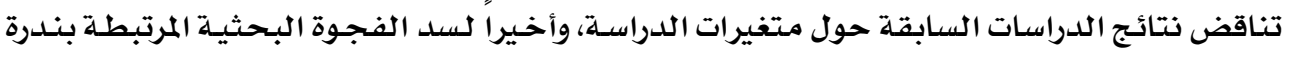

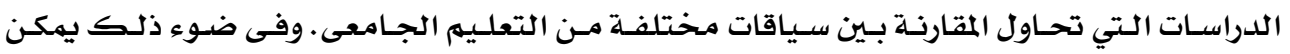

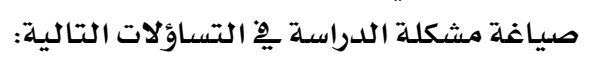

\section{تساؤلات الدراسة:}

\section{يمكن تحديد مشكلة الدراسة الحالية يِّ الإجابة على التساؤلات التالية:}

1- هل توجد فروق بين متوسطات درجات طلاب الفرقة الأولى وطلاب الفرقة الرابعة بالتعليم

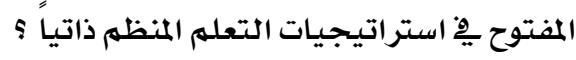

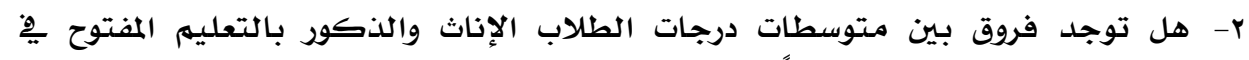

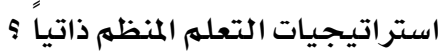

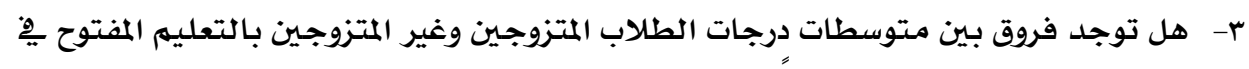

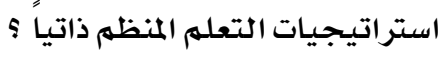

\section{أهد|ف الدراسة: أنجيات}

\section{تهدف الدراسة الحالية إلى ما يلى:}

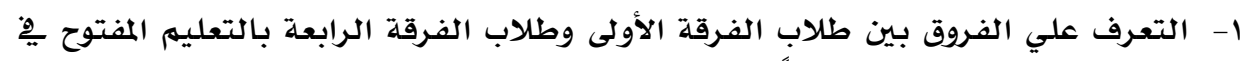

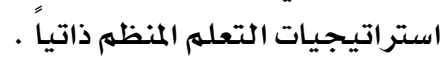

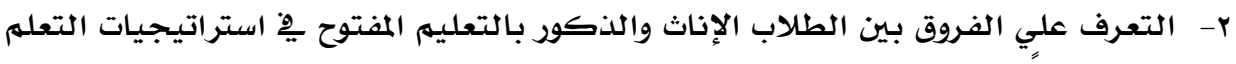


مجلة بحوث التربية النوعية - علد rأ - أبريل r.17 م

r- التعرف علي الفروق بين الطلاب المتزوجين وغير المتزوجين بالتعليم المفتوح هِِ استراتيجيات

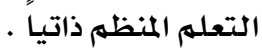

\section{أهمية الدراسة:}

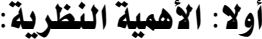

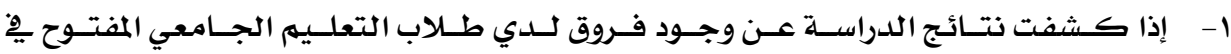

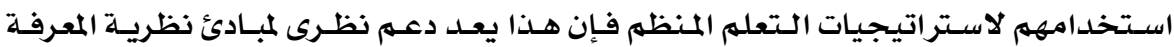

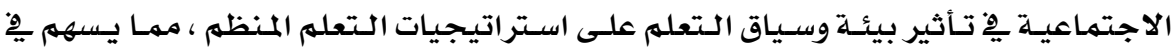
تعمق دراسة العوامل السياقية الاجتماعية التعليمية ذات التأثير على تعلهم الطلاب.

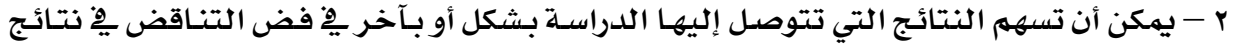

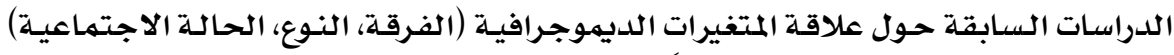
بمتغير استراتيجيات التعلهم المنظم ذاتياً .

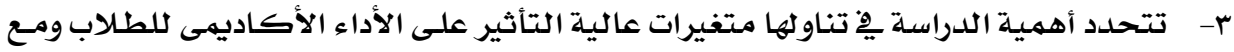

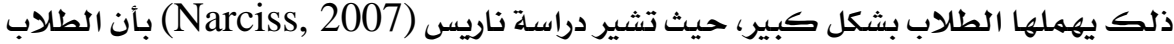

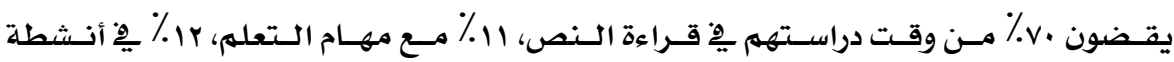

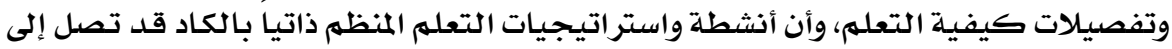
أقل من ا ٪ من أوقاتهم.

\section{الأهمية التطبيقية:}

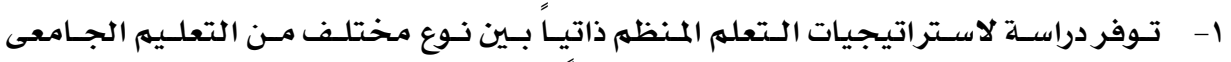

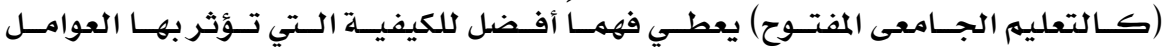

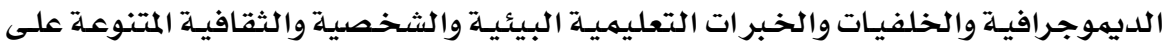

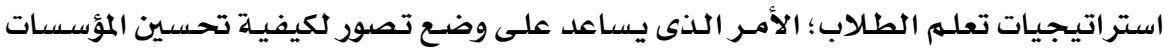

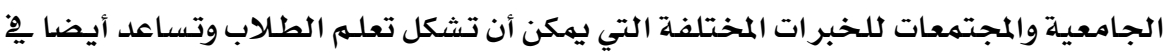

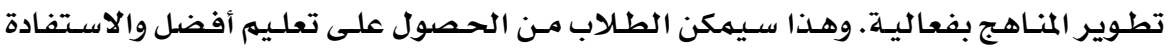

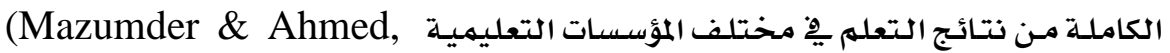
.2014; Mazumder \& Dakeev, 2015)

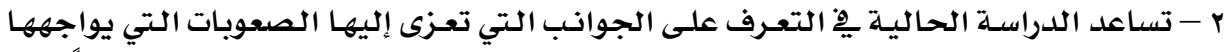

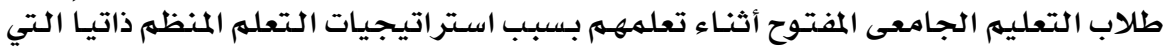

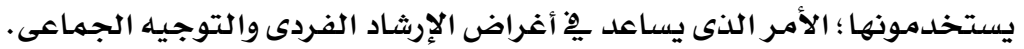


• استراتيجيات التعلم المنظم ذاتياً Self-Regulated Learning Strategies:

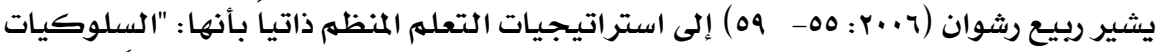

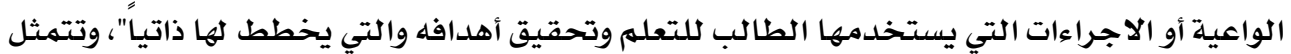
مِ : التسميع Rehearsal

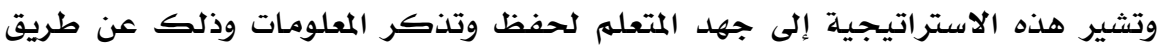

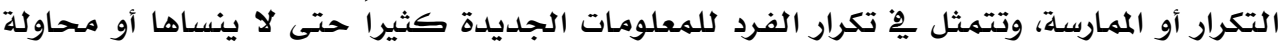

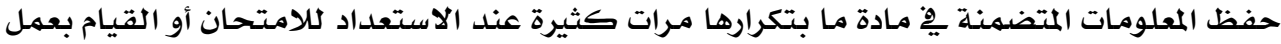

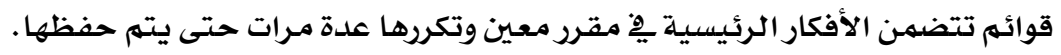

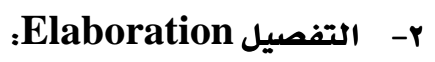

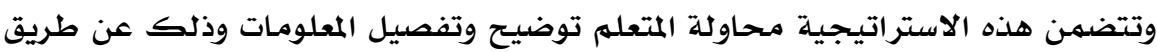

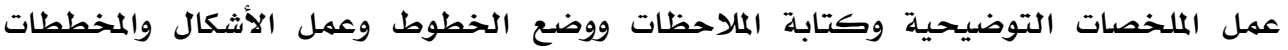

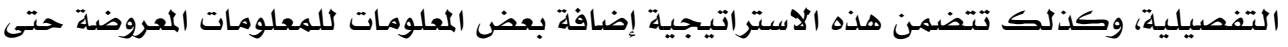
تصبيح ذات معنى أو تصبيح مفهوممة بالنسبية للفرد.

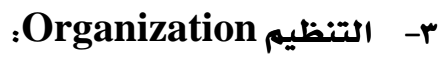
وتتضمن هذه الاستراتيجية محاولة المتعلم الظاهرة والضمنية لإعادة تنظيهم وترتيب

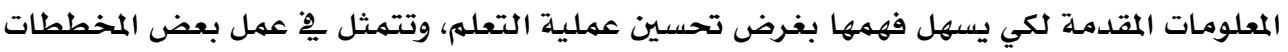

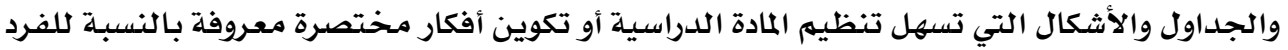

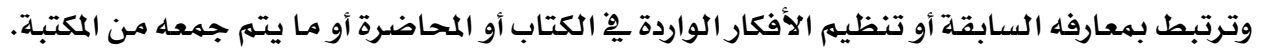

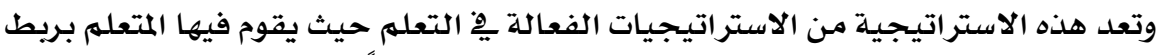

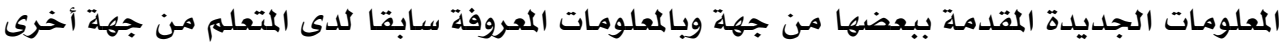
يسهـه يُّ تكوين بنيات معرفية أكثر استقرارا. ع- التخطيط ووضع الأهداف Goal Setting and Planning وهي تشير إلى تحديد المتعله لأهدافه من القيام بعمل ما وإعداده لخطة لتحقيقها، ويتمثل

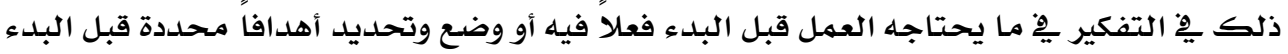

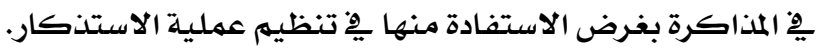




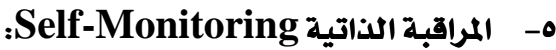

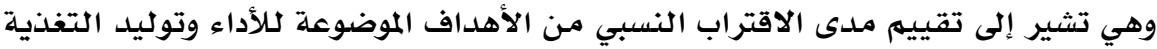

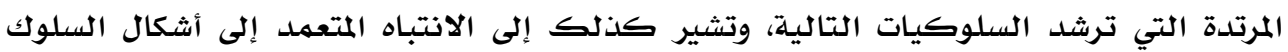

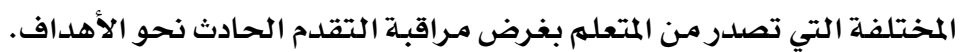

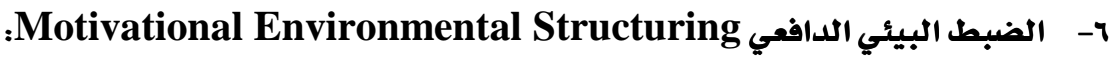

تعد استراتيجية الضبط البيئي الدافعى بجانب أهميتها ِِّ تنظيم بيئة التعلهم المكانية لها

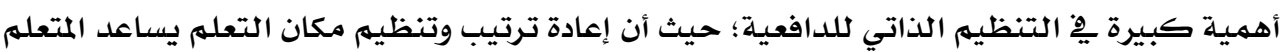

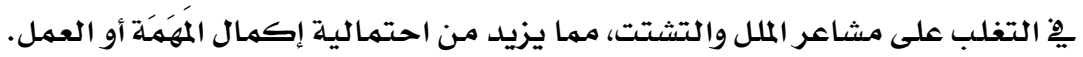

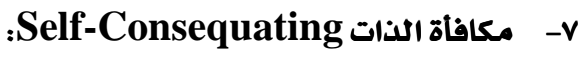

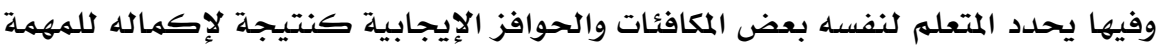

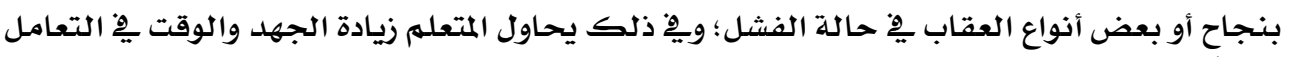

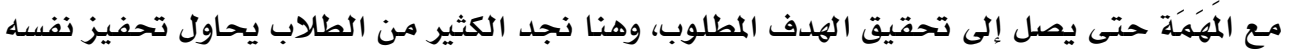

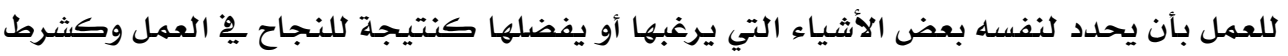
كلاستمرار فيه.

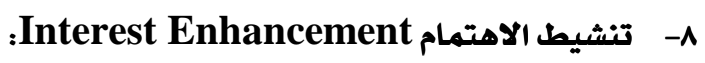

عندما يتعرض الفرد لمَهَمَة ما تتكون لديه محددات معينة عن هذه المهام والتي تؤثر على ألى

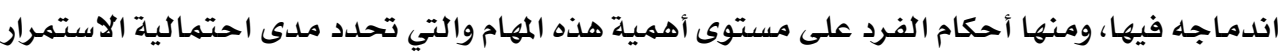

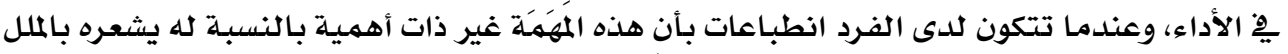

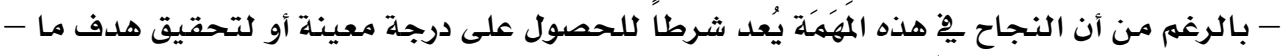

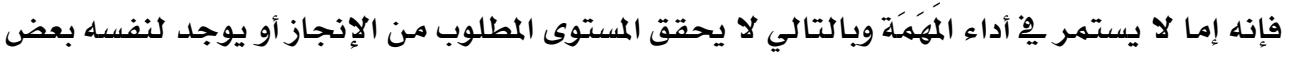

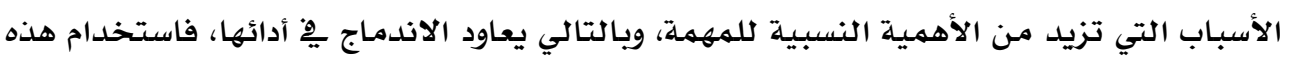

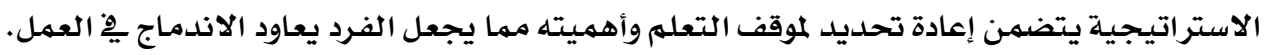

9- حوار الذات عن الإتقان Mastery Self-Talking: وفيها يحاول المتعلم استخدام الأفكار أو الحديث إلى الذات للوصف أو للتوضيح أو للتأكيد

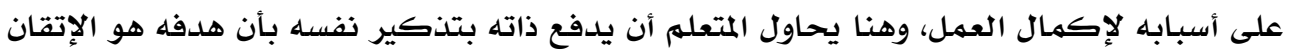

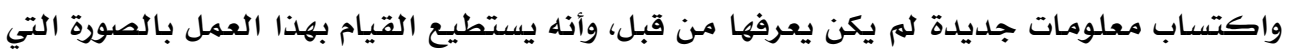

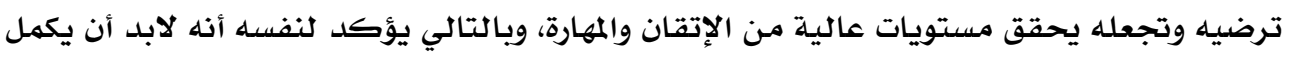
العمل أو المَهَمَةَة.

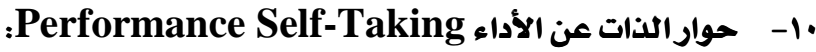
وفيها يحاول المتعلم استخدام الأفكار أو الحديث إلى الذات للوصف أو للتوضيح أو للتأكيد

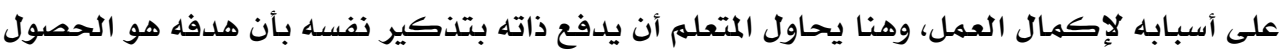


على درجات مرتفعة أو التفوق على الأقران؛ أي أن الفرد يؤكد لنفسـه ضرورة أن يكمل العمل أو المَهَمَة

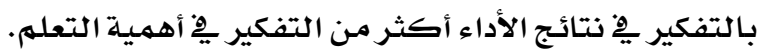

\section{Environmental Structuring الضبط البيئير}

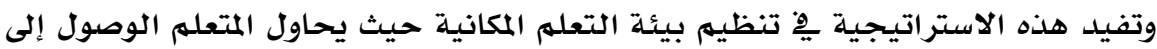

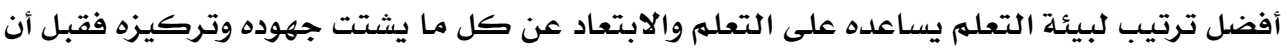

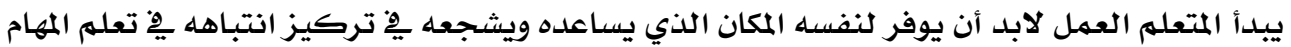

$$
\text { موضوع التعلهم. }
$$

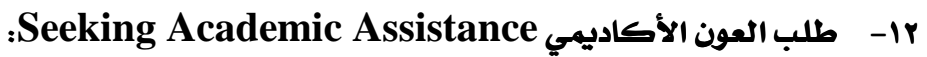

وتتمثل ِِّ سعي المتعلهم للحصول على المساعدة من الآخرين كالأقران والمعلمين والأسرة،

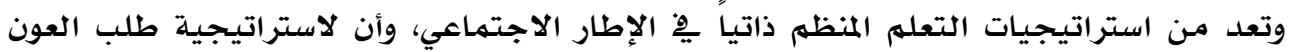

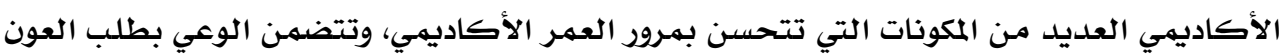

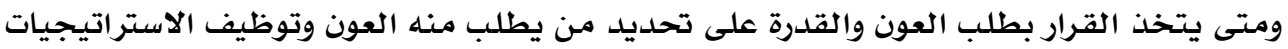
الفعالة للحصول المساعدة.

وتعد هذه الاستراتيجية من استراتيجيات التعلهم الفعالة والتي يلجأ إليها المتعلهم عندما

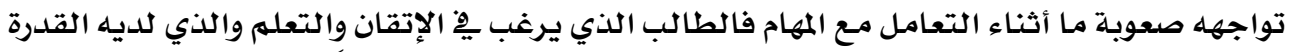

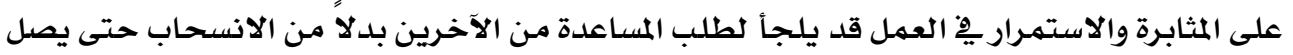

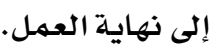

\section{Peers Learning تعلم الأقران}

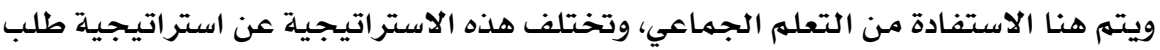

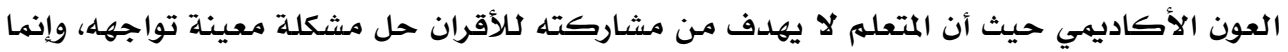

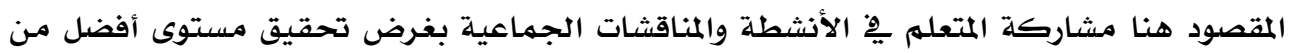
التعلهم.

\section{: Information Seeking إلبحث عن المعلومات}

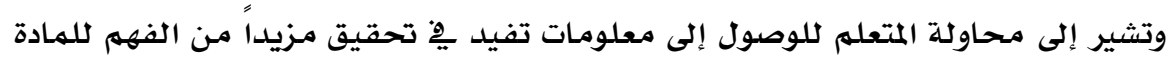

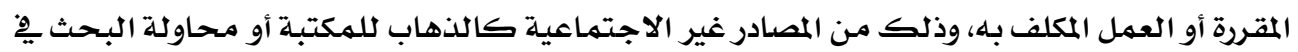

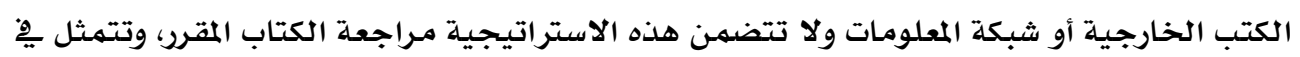

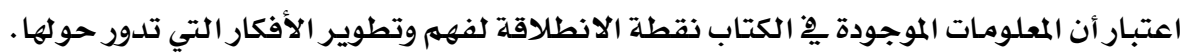

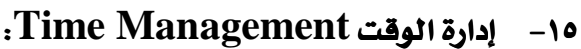

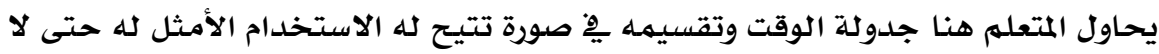

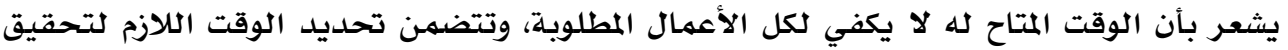

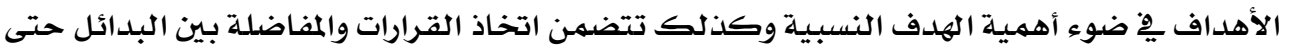

\section{4.}


يتوصل الفرد إلى جدولة الوقت المتاح بصورة تتيح الاستخدام الأمثل له، ويعد الوقت من محددات

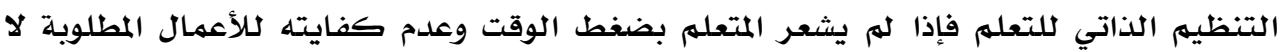
يلهاً لتتنظيمه.

Keeping Records

تشير هذه الاستراتيجية إلى محاولة المتعلهم عمل بعض التقارير والسجلات التي يسجل

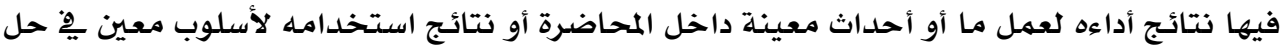

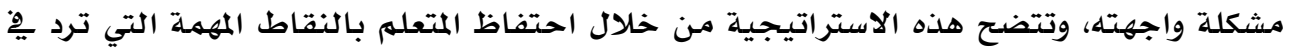

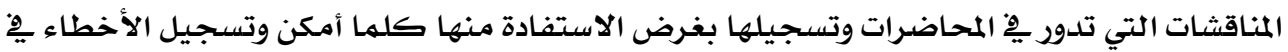

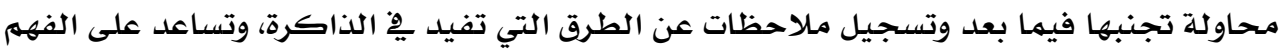

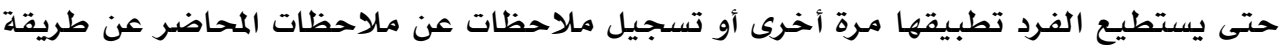
الإجابة هِيْ الامتحان.

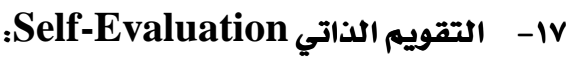

وهي من المكونات المهمة للتعلهم المنظم ذاتياً وتشير إلى مقارنة المتعلهم للمخرجات بالمعايير

الموضوعة للأداء أو بالأهداف المراد تحقيقها.

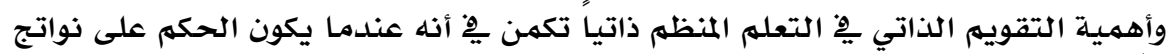

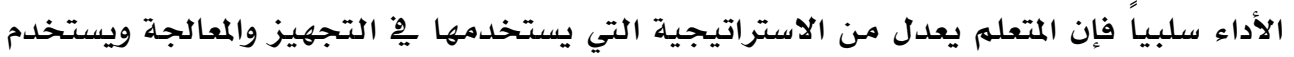

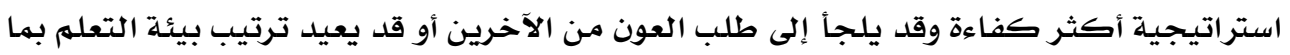

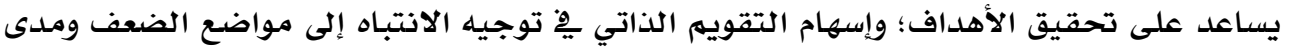

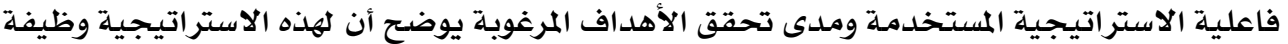

$$
\text { ما وراء معرفية بجانب وظيفتها المعرفية. }
$$

وتقاس إجرائيا ٌِِ هذه الدراسة بالدرجة التي يحصل عليها الطالب على استبيان

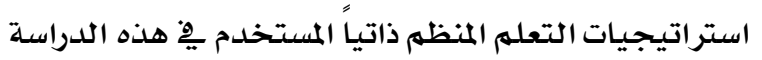

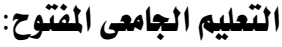

يعرف ويبر لى وهافيندين (Webberley \& Haffenden, 1987: 138) التعليهم المفتوح

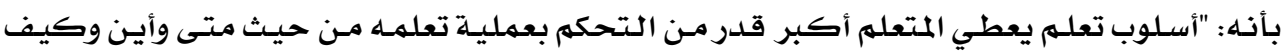

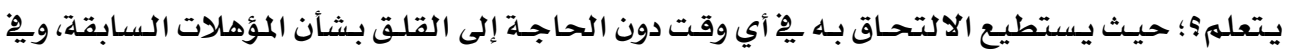

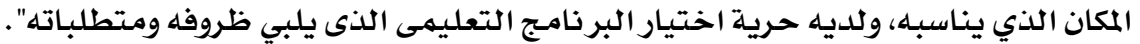

\section{طلاب الجامعة:}

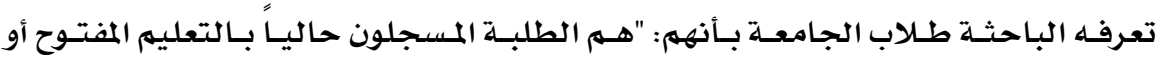

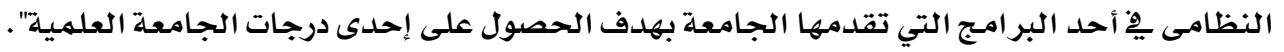




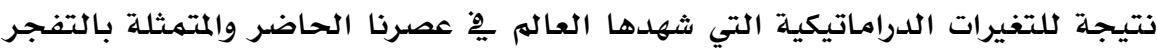

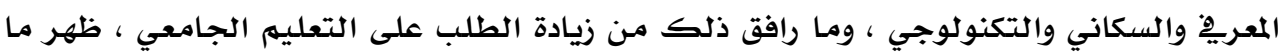

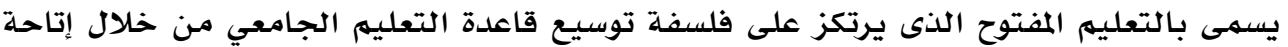

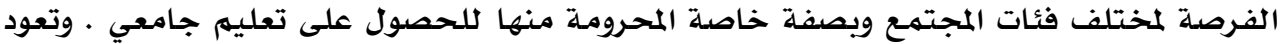

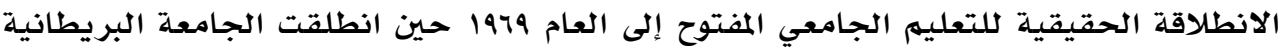

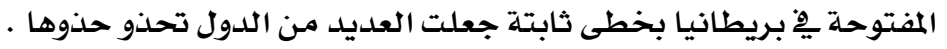

وقد ظهرت فكرة الجامعة المفتوحة ِِّ الستينيات من هذا القرن على يد " هارولد ويلسون "

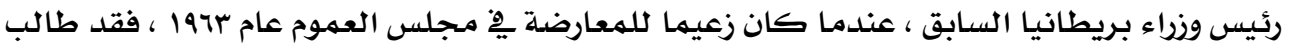

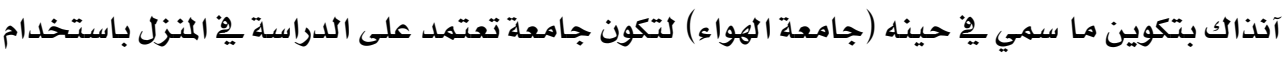

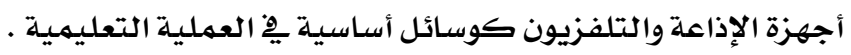

وانتشرت فكرة التعليم المفتوح فيما بعد ِِّ دول عديدة تبنت المفهوم وأدركت أن بإمكانها

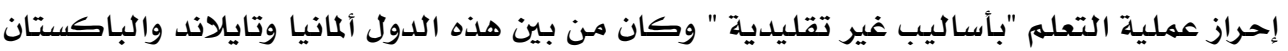

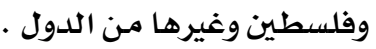

هدفت دراسـة أبلارد وليبشولتز (Ablard \& Lipschultz, 1998) إلى فحص العلاتئة

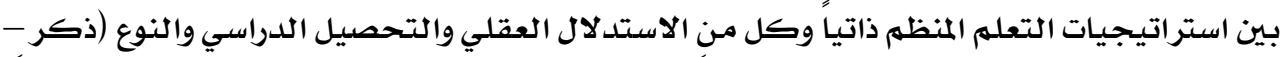

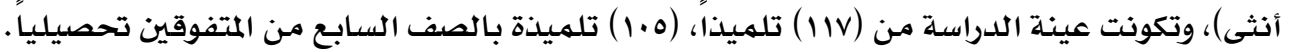

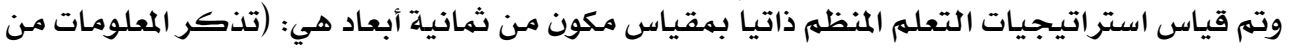

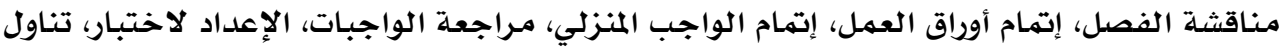

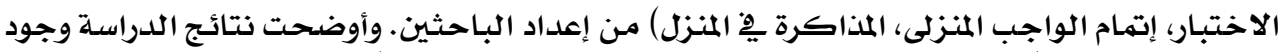

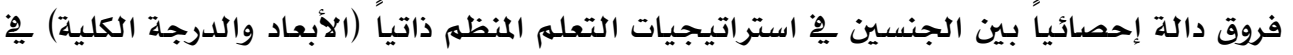
اتجاه الإناث.

وبحثت دراسة بيدجيرانو (Bidjerano, 2005) الفروق بين الجنسين فى استراتيجيات

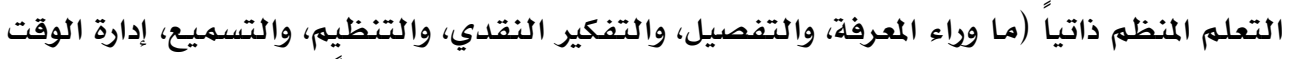

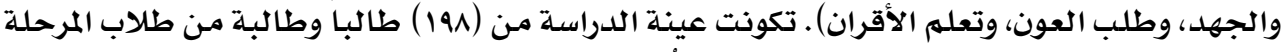
الجامعية يِّ شمال شرق الولايات المتحدة. طبق عليهم استبيان الاستراتيجيات الدافعة للتعلهم من إعداد بينتريث وآخرون (MSLQ)

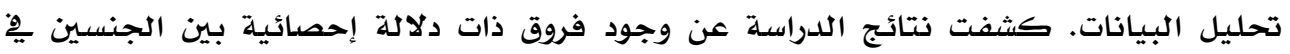

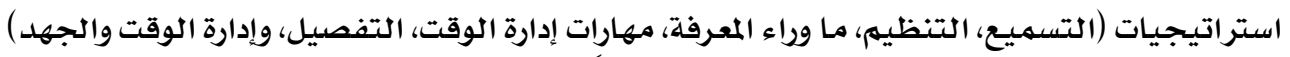

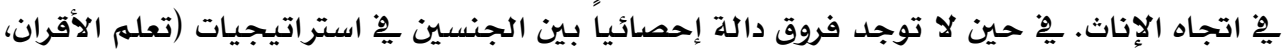
طلب العون، والتفكير النقدي). 


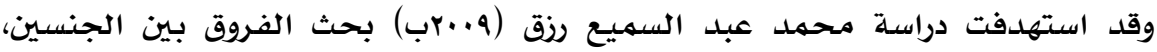

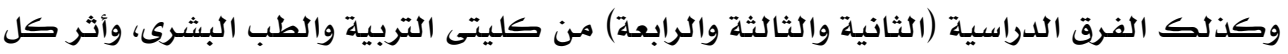

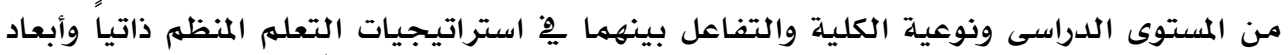

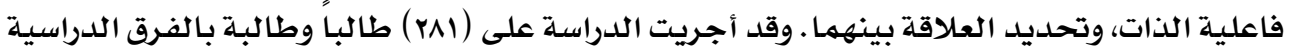

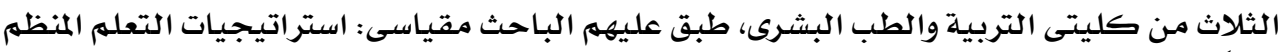

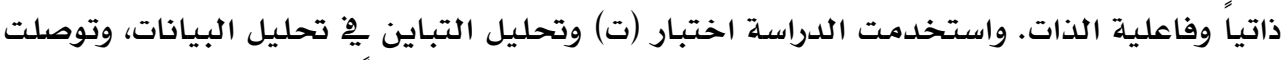

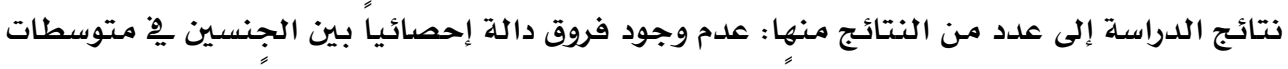

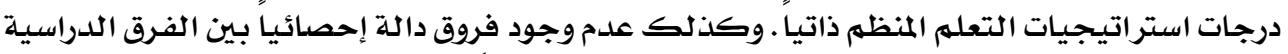

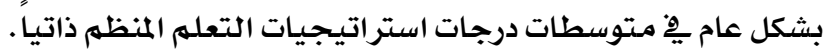

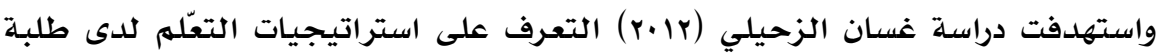

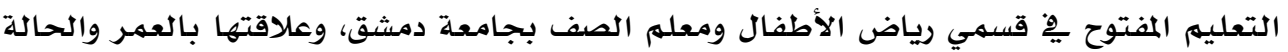

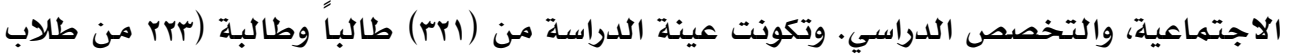

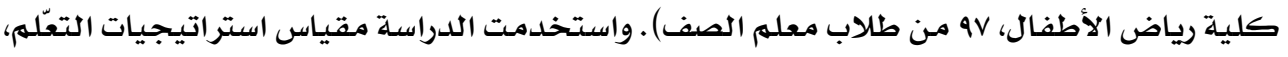

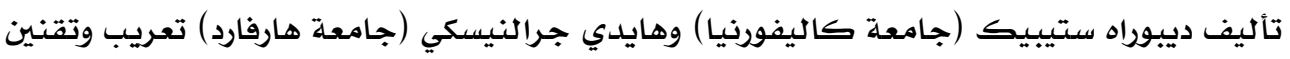

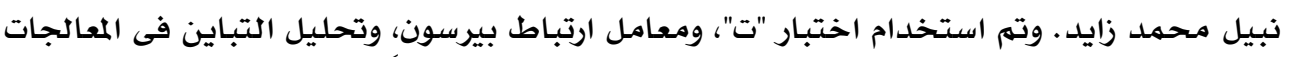

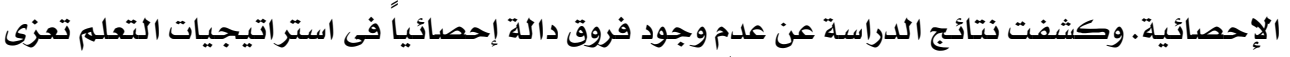

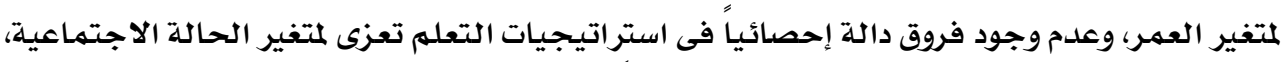

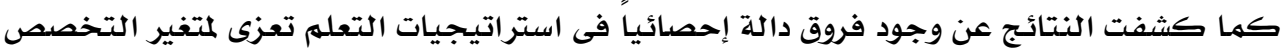

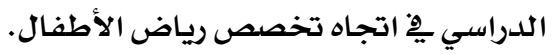

\section{اجراءات الدراسة}

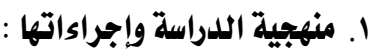

يمكن تلخيص إجراءات الدراسـة الحالية يْ النقاط التالية :-

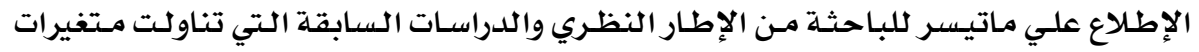

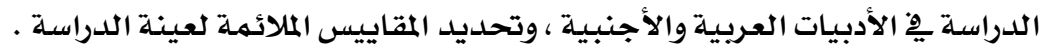

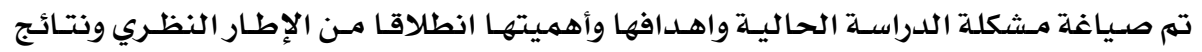

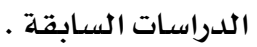

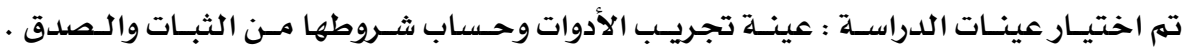

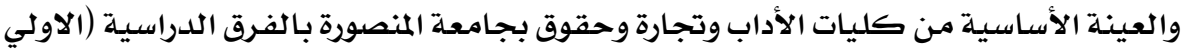

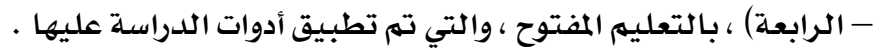

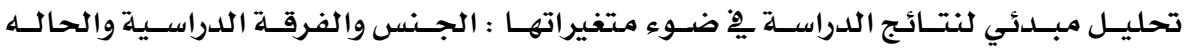

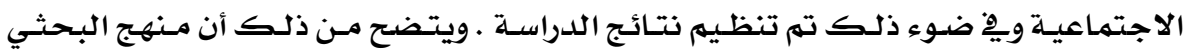

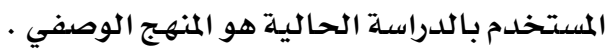




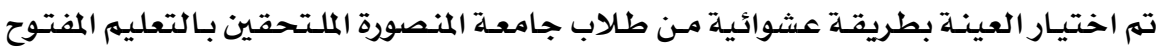

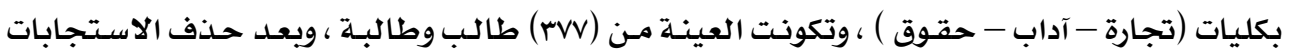

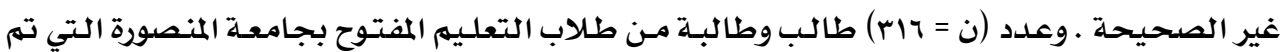

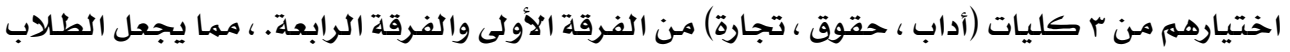

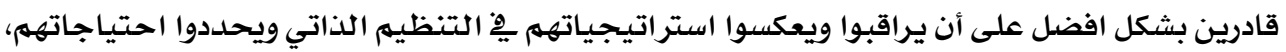

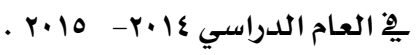

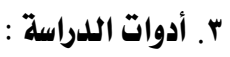

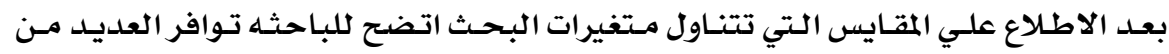

مقايس استراتيجيات التعلهم الذاتي واختارت منها الباحثيه :

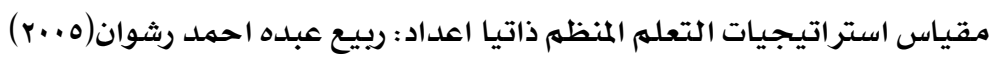

$$
\text { ا- مقايس استراتيجيات التعلم المنظم ذاتياً: }
$$

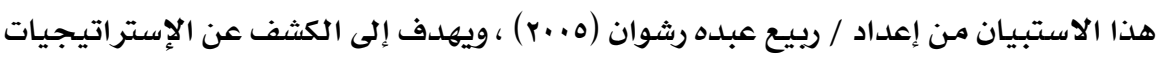

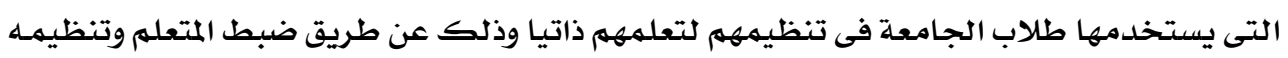

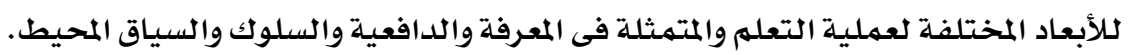

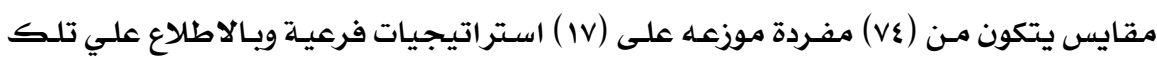

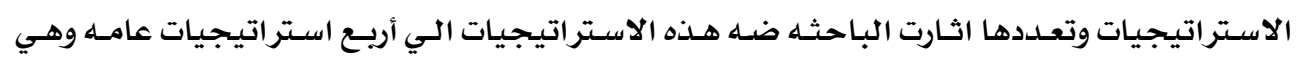

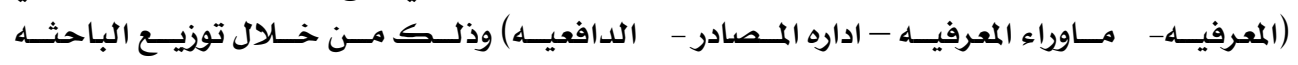

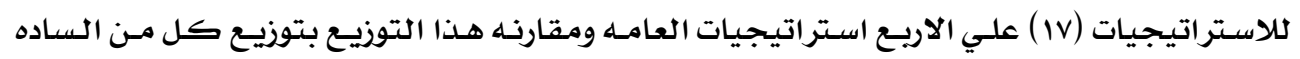

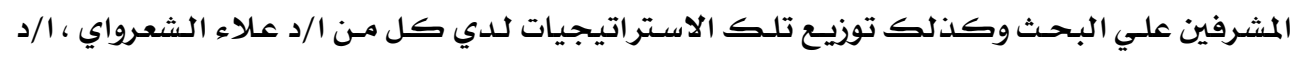

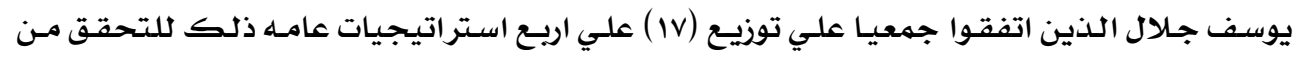

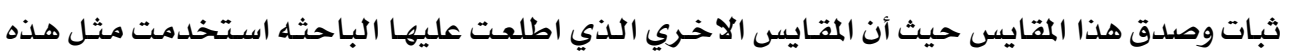
الاستر اتيجيات العامـه .

الشروط السيكومترية لمقياس استراتيجيات التعلم المنظم ذاتيا: • صدق المقياس:

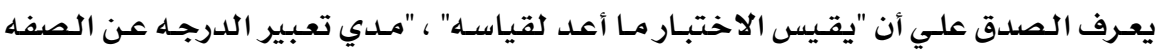

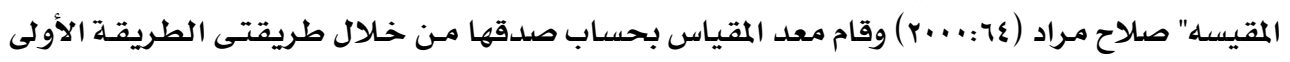

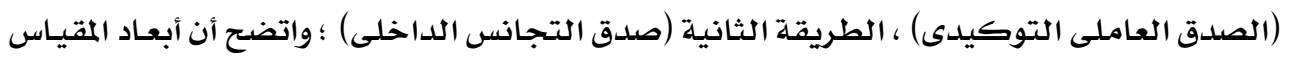

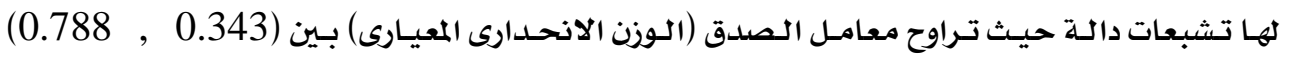


وكذلك لها تأثيرات دالة عند مستوى 0.01 حيث تزيد النسبـة الحرجة عند 2.58 مما يؤكد صداق أبعاد المقياس الحالى وتشبعها على عامل كامن واحد هو التعلى داتله المنظم ذاتيا.

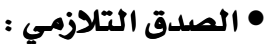

استحدمت الباحثه الحاليه اسلوب الصداق التلازمي وذلك مـن خـلال حسـاب الارتبـاط بـين

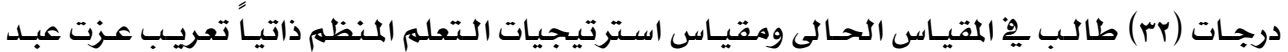

$$
\text { الحميد (1999). }
$$

ويوضح جدول التالي(1) نتائج:

جدول (1)

معاملات الارتباط بين درجات الطلاب على مقياس استراتيجيات التعلم المنظم ذاتياً إعداد (رييع عبده أحمد رشوان) ودرجاتهم على مقياس الاستراتيجيات التعلم المنظم ذاتيا تعريب (عزت عبد الحميد)

\begin{tabular}{|c|c|c|c|c|}
\hline الدافعية & إدارة المصادر & ما وراء المعرفية & المعرفي & \\
\hline$\cdot|v|$ & $*,\{\cdot 0$ & $* *, 091$ & *.,हr. & المعرفية \\
\hline$* *$, oor & *., ras & $*_{\bullet, \xi \bullet r}$ & $*_{\bullet, \text { \&rr }}$ & ما وراء المعرفية \\
\hline$* *_{\bullet, \text { ovo }}$ & $*, r \wedge 1$ & $\cdot, r \leqslant 7$ & $* *$, orr & إدارة الوقت والبيئة \\
\hline \multicolumn{5}{|c|}{ ** دال عند مستوى (ا+,•) } \\
\hline
\end{tabular}

يتضح من الجدول السـابق أن معاملات الارتباط ومتوسطة القيمهل ودالـه، ، أخـذا يِّ الاعتبـار

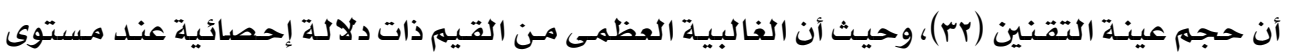

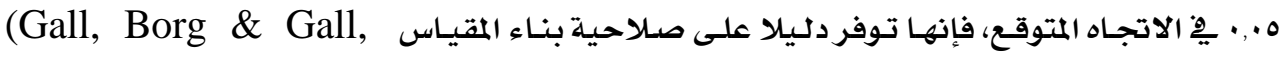

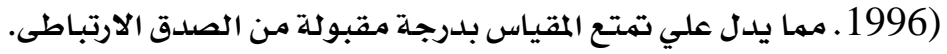

$$
\text { • (الاتساق الداخلى: }
$$

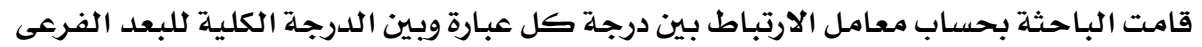

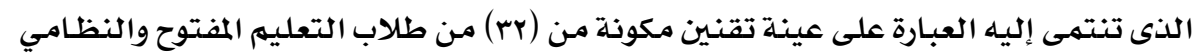

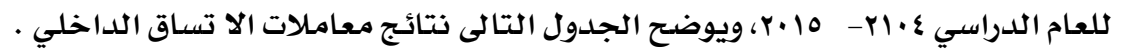




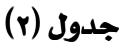

معاملات الارتباط بين درجة كل مفردة ودرجة البعد الذى تنتهى إليه المفردة لمقياس استراتيجيات التعلم المنظم ذاتياً

\begin{tabular}{|c|c|c|c|c|c|c|c|c|c|}
\hline \multicolumn{2}{|l|}{ التخطيط } & \multicolumn{2}{|l|}{ المراقبة } & \multicolumn{2}{|l|}{ التنظيم } & \multicolumn{2}{|l|}{ التفصيل } & \multicolumn{2}{|l|}{ التسميع } \\
\hline معامل الارتباط & a & معامل الارتباط & ค & معامل الارتباط & $\hat{\imath}$ & معامل الارتباط & ค & معامل الارتباط & A \\
\hline$* *,\{97$ & $r$ & $* *$, orA & ir & **., ๆ & 1 & $*_{\bullet, \xi T Y}$ & $\wedge$ & 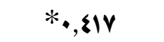 & rr \\
\hline$* *, \mathrm{vr}$. & rr & $* *, 0, v$ & YE & $* *$, VY & in & $* *, 7 \cdot 1$ & iv & **, rar & rr \\
\hline$* *, 0 \wedge \varepsilon$ & $r \wedge$ & $*_{\bullet, Z Y r}$ & H & $* *, 790$ & $r$. & $* *,, 10 \xi$ & $r q$ & $* *, \eta\rceil$ & rq \\
\hline \multirow[t]{3}{*}{ 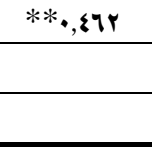 } & rA & $* *, 09$. & rq & $* *,\{\wedge r$ & $\Sigma 7$ & $* *, y \geqq 1$ & 70 & **, orr & 01 \\
\hline & & $* *,\{\wedge\rceil$ & $\xi V$ & & & & & & \\
\hline & & $* *,, 7 \leqslant 1$ & 77 & & & & & & \\
\hline \multicolumn{2}{|c|}{ تنشيط الاهتمام } & \multicolumn{2}{|c|}{ حوار الذات عن الأداء } & \multicolumn{2}{|c|}{ حوار الذات عن الكفاءة } & \multicolumn{2}{|c|}{ الضبط البيئي الدافعى } & \multicolumn{2}{|c|}{ مكافأة الذات } \\
\hline معامل الارتباط & ค & معامل الارتباط & ค & معامل الارتباط & $\hat{2}$ & معامل الارتباط & ค & معامل الارتباط & ค \\
\hline$*_{\bullet}, r r r$ & r. & $*$, rqq & r & $* *,, \eta \wedge$ & 9 & $* *$, , YoY & $1 \varepsilon$ & $* *, \wedge r \eta$ & §o \\
\hline$* *, 011$ & $\llbracket \varepsilon$ & $* *$, , ovr & sr & $* *_{\bullet}, 1 \leqslant 7$ & ro & 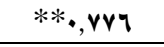 & rr & $* *, \Lambda \cdot V$ & or \\
\hline$* *,\{\wedge \Lambda$ & ar & $* *$, v 70 & or & $* *$, ovy & rv & $* *, r, r$ & $\leqslant 9$ & $* *, \wedge$, & 91 \\
\hline$* *,, 7 \wedge$. & 79 & $* *, 771$ & Vr & $* *$, ory & $\xi r$ & $* *$, , 794 & 7. & $* *, \vee \vee \leqslant 0$ & vi \\
\hline **, ๆ & V乏 & & & $* *$, * §१४ & 00 & & & & \\
\hline \multicolumn{2}{|c|}{ الاحتفاظ بالسجلات } & \multicolumn{2}{|c|}{ البحث عن المعلومات } & \multicolumn{2}{|c|}{ تعلم الأقران } & \multicolumn{2}{|l|}{ طلب العوز } & \multicolumn{2}{|c|}{ الضبط البيئى } \\
\hline معامل الارتباط & $\hat{\rho}$ & معامل الارتباط & $\hat{\imath}$ & معامل الارتباط & $\hat{\imath}$ & معامل الارتباط & $\hat{\imath}$ & معامل الارتباط & ค \\
\hline$* *_{\bullet, \Delta 9 V}$ & $r$ & $* *_{,}$, oor & $v$ & $* *, 070$ & 0 & $*_{\text {*, rar }}$ & $r y$ & $* *_{\bullet},\{\wedge \uparrow$ & 9 \\
\hline$* *$, หฯ & r乏 & $* *, \mathrm{rr}$ & ir & $* *, \gamma \cdot q$ & 1. & $* *, 711$ & 07 & $* *$, , $r q$ & $M$ \\
\hline$* *, 7,7$ & or & **, , tro & $\{\Lambda$ & $* *$, , vos & 19 & $* *, 0.0$ & Tr & $* *$, Уด१ & $0\}$ \\
\hline \multirow[t]{9}{*}{$* *, r, r$} & 78 & $* *_{\bullet}, 1 \leqslant 7$ & Vr & $* *$, Y r & $\xi$ & $* *_{,}, 014$ & v. & $* *,, 1 \leqslant 7$ & IV \\
\hline & & & & $\left.*_{,}, \xi \circ\right\rceil$ & $\$ 1$ & & & & \\
\hline & & & & & & \multicolumn{2}{|c|}{ تقويم الذات } & \multicolumn{2}{|c|}{ إدارة الوقت } \\
\hline & & & & & & معامل الارتباط & $\stackrel{2}{+}$ & معامل الارتباط & $\stackrel{2}{2}$ \\
\hline & & & & & & $* *$, , $\vee Y$ & 10 & $*_{*}^{*},\{91$ & $\varepsilon$ \\
\hline & & & & & & $* *_{,}$, ovy & 01 & $*_{\text {, ITr }}$ & 11 \\
\hline & & & & & & $* *, 099$ & 89 & $* *, \eta \uparrow$. & 17 \\
\hline & & & & & & $* *, 7,9$ & 71 & $* *$, rrr & ro \\
\hline & & & & & & & & $* *, \wedge r$. & 0. \\
\hline
\end{tabular}

يتضح من الجدول السـابق أن معامل الارتباط بين كل مفردة من المفردات والدرجة الدئ الكلية

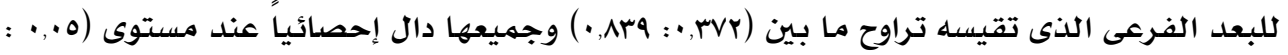


مجلة بحوث التربية النوعية - علدد باء - أبريل r.17

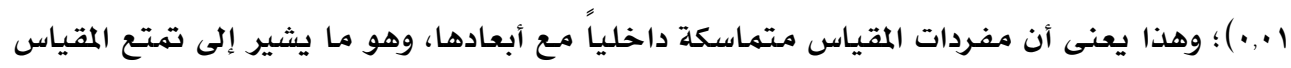

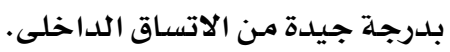
• ثبات المقياس:

قام معد المقياس بحساب ثباتها بطريقتين ، الأولى، معامل ثبات ألفا كرونباخ وقد تراوحت

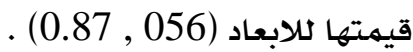

قامت الباحثه الحاليه بحساب معامل ثبات ألفا - كرونباخ Cronbach - Alpha لابعاد المقياس وذلك بتطبيق علي (rr) طالب من طلاب التعليم المفتوح وحساب قيمهه معامل ألفا لكل

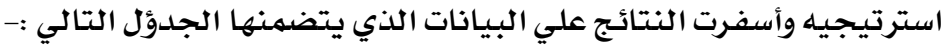

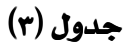

معاملات ثبات مقياس ابعاد استراتيجيات تعلم المنظم ذاتياً باستخدام معادلة ألفا - كرونباخ

\begin{tabular}{|c|c|c|c|}
\hline معامل ألفاكرونباخ & البعد & معامل ألفاكرونباخ & البعد \\
\hline$\cdot, \mathrm{rl}$. & الضبط البيئى & $\cdot, \mathrm{V} \leqslant \mathrm{Y}$ & التسميع \\
\hline •, YVY & طلب العوز & $\cdot, v+1$ & التفصيل \\
\hline דצ', & تعلم الأقران & •, Y19 & التنظيي \\
\hline 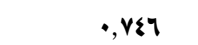 & البحث عن المعلومات & $\cdot, \mathrm{V} \leq \varepsilon$ & المراقبة \\
\hline$\cdot, v \leqslant 7$ & الاحتفاظ بالسجلات & •, 794 & التخطيط \\
\hline •,var & إدارة الوقت & $\cdot, 0 . r$ & مكاقأة الذات \\
\hline \multirow[t]{4}{*}{ •, VYE } & تقويم الذات & $\cdot, \wedge 17$ & الضبط البيئي الدافعى \\
\hline & & •, $\vee \wedge 9$ & حوار الذات عز الكفاءة \\
\hline & & •, VRr & حوار الذات عن الأدوار \\
\hline & & •,YYI & تنشيط الاهتمام \\
\hline
\end{tabular}

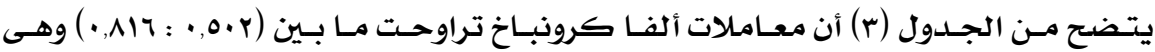

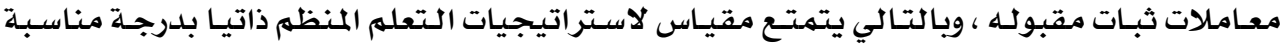
من الثبات . معاتلات تيات

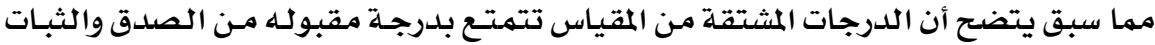

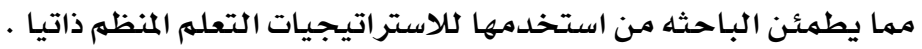
نتائج الدراسة:

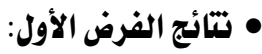

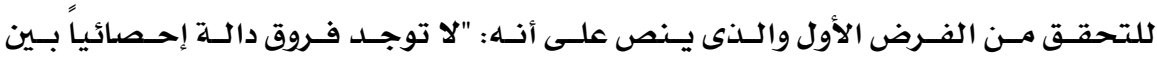

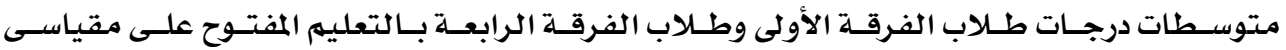

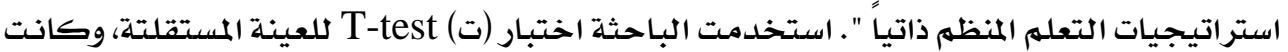

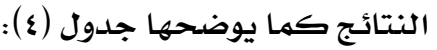




\section{جدول (๕) (1)}

قيمة (ت) ودلالتها للفروق بين متوسطات درجات طلاب الفرقة الأولى وطلاب الفرقة الرابعة بالتعليم المفتوح على مقياس استراتيجيات التعلم المنظم ذاتياً

\begin{tabular}{|c|c|c|c|c|c|c|}
\hline \multirow[t]{2}{*}{ مستوى الدلاية } & \multirow[t]{2}{*}{ قيمة (ت) } & \multicolumn{2}{|c|}{ 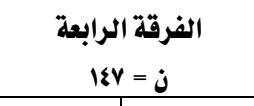 } & \multicolumn{2}{|c|}{ 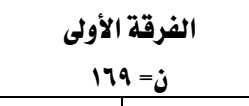 } & \multirow{2}{*}{ 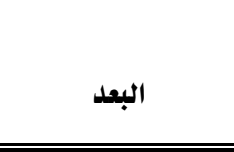 } \\
\hline & & $\varepsilon$ & 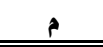 & $\varepsilon$ & 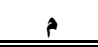 & \\
\hline \multicolumn{7}{|c|}{ استراتيجيات التصلم المنظم ذاتياً } \\
\hline غير دال & $\cdot, 0 \cdot 1$ & $r, \cdots r$ & $14, \cdot 1 \varepsilon$ & $r, \bullet r$ & Ir,Ir. & التسميع \\
\hline 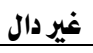 & •, rar & $1,7 \leqslant \vee$ & $1 \%, v 79$ & 1,77 . & $\mathbb{M}, \wedge \varepsilon \cdot$ & التفصيل \\
\hline غير دال & 1,701 & $r, 00$ & $11, \xi+1$ & r,trr & $1 ., 90 \mathrm{r}$ & التنظيي \\
\hline غير دال & $1, \cdot r q$ & r,arA & $17, \cdot 71$ & $r, \cdot 91$ & $10, \mathrm{r} 1$. & المراقبة \\
\hline 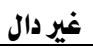 & •, orr & $Y, \$ 17$ & 11, \&Yq & $r,\{+1$ & 11, YA₹ & التخطيط \\
\hline 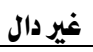 & $\bullet, 00$ & $r, \$ 9 \Lambda$ & $11, r \varepsilon$. & $r, r v \cdot$ & 11,119 & مكافأة الذات \\
\hline غير دال & $1,|\varepsilon|$ & Y,Y৭Y & $1 \cdot, \wedge \vee \wedge$ & r,YrY & $11, r \varepsilon r$ & الضبط البيئي الداففى \\
\hline غير دال & $1, r m 1$ & $r, 0 \leqslant r$ & Ir,arr & $r, 0.9$ & Ir,os\& & حوار الذات عن الكفاءة \\
\hline$\cdot, \cdot \cdot 1$ & \&,TrA & r, Irv & Ir, IAE & $r, r \leqslant 0$ & $1 \cdot, 9 v \cdot$ & حوار الذات عن الأداء \\
\hline$\cdot, \cdot 0$ & r, YOQ & r,VI\& & $1 \varepsilon, \xi \cdot 1$ & $r, \gtrless q \wedge$ & $1 r, v \leqslant 7$ & تنشيط الاهتمام \\
\hline غير دال & $\cdot$, AOr & r, RVr & Ir, $\bullet 0\}$ & $r, \bullet \vee \wedge$ & Ir,rrv & الضبط البيئي \\
\hline غير دال & $\cdot,\{9 \mid$ & $r, \cdot \varepsilon r$ & $1 \cdot, 9 \cdot 0$ & r, rrA & $11, \cdot 0 r$ & طلب العوز \\
\hline غير دال & 1, ron & $r, r \cdot r$ & $1 E, \cdot A r$ & r, Irr & $1 r, v \cdot \varepsilon$ & تعلم الأقران \\
\hline غير دال & $\cdot, 9 \vee \varepsilon$ & r,qrr & II, rir & r,YTE & $11, \cdots$ & البحث عن المعلومات \\
\hline غير دال & $\cdot, \wedge r I$ & Y,ร7ฯ & $1 \cdot, 909$ & Y,YOA & $11,1 \mathrm{VA}$ & الاحتفاظ بالسجلات \\
\hline غير دال & $1, r \cdot v$ & $r, 0 \wedge 1$ & Ir, 10 & $r, 0 \cdot \wedge$ & $|r, r q|$ & إدارة الوقت \\
\hline غير دال & - Aro & r, רrr & $11, \vee v y$ & r,ZYr & 11, orq & تقويم الذات \\
\hline
\end{tabular}

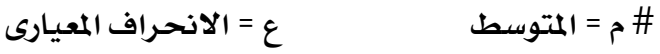

$$
\begin{aligned}
& \text { يتضح من جدول (ع) ما يلى: }
\end{aligned}
$$

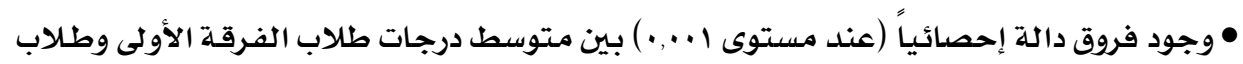

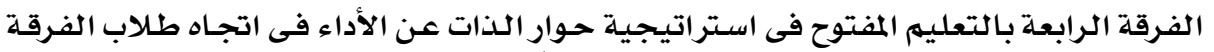

$$
\text { الرابعة على مقياس استراتيجيات التعلهم المنظم ذاتياً. }
$$

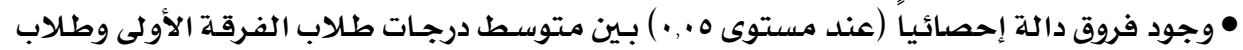

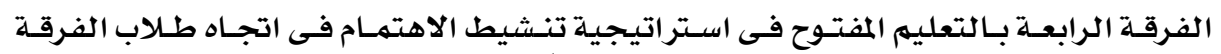
الرابعة على مقياس استراتيجيات التعلهم المنظم ذاتياً. 
• لا توجد فروق دالة إحصائياً بين متوسطات درجـات طلاب الفرقـة الأولى وطلاب الفرقـة الرابعـة

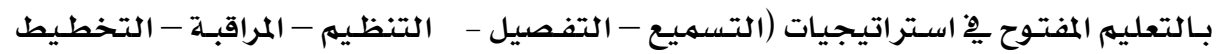

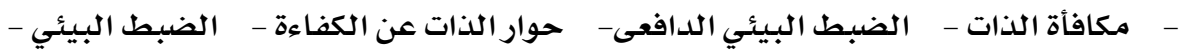

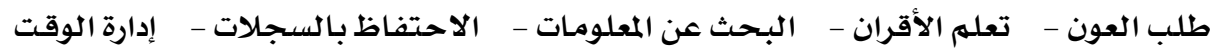

$$
\text { تقويم الذات) على مقياس استراتيجيات التعلهم المنظم ذاتياً. }
$$

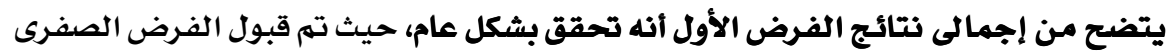

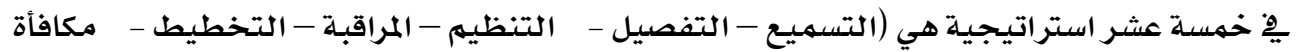

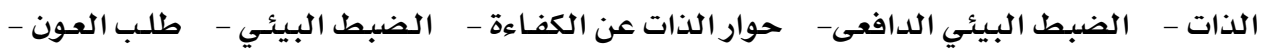

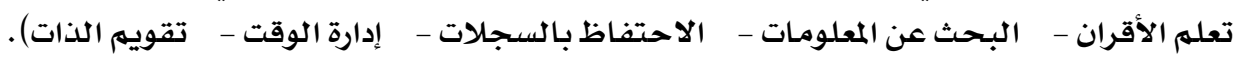

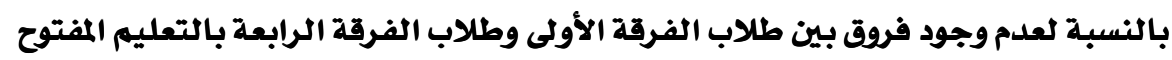

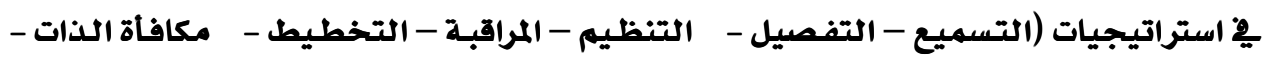

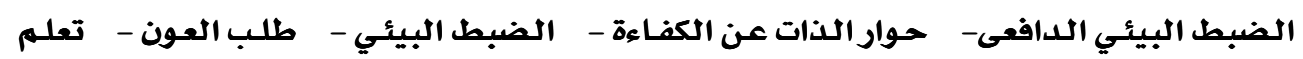

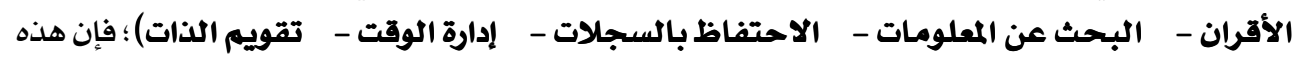

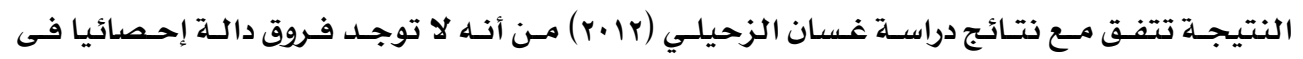

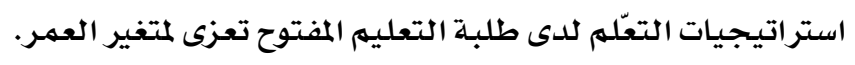
وتفسر الباحثة ذلك؛ بأن طلاب التعليم المفتوح قبل أن يلتحقوا بـه قد لا يكون لديهم

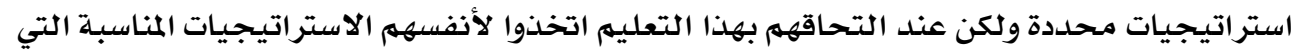

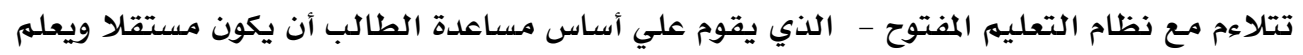

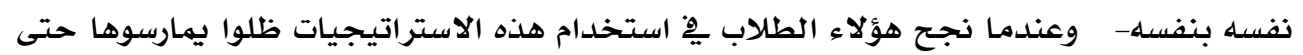
الفرقة الرابعة.

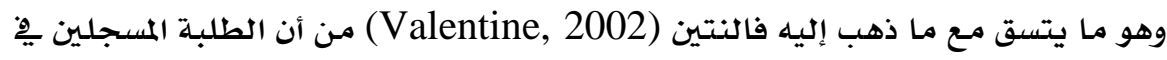

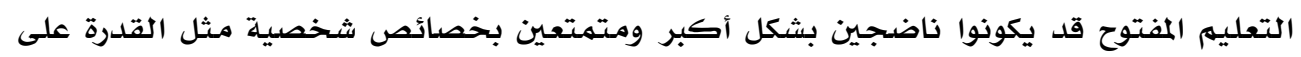

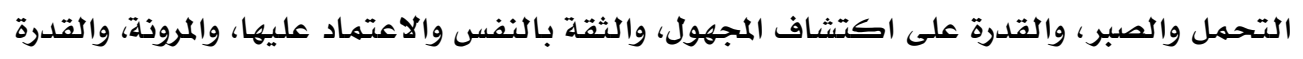

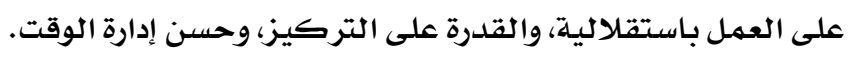
كما يتضمن نظام التعليم المفتوح إجراءات تجعل من الممكن للأفراد أن يتعلموا بالزمان

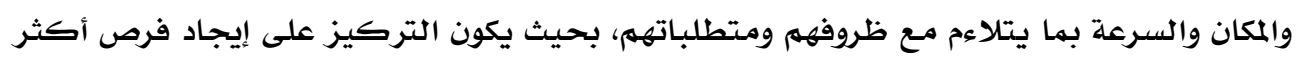

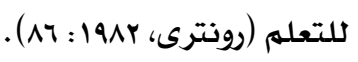

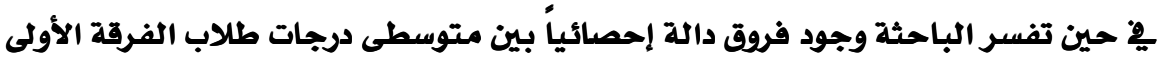

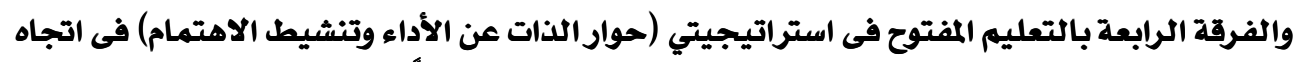

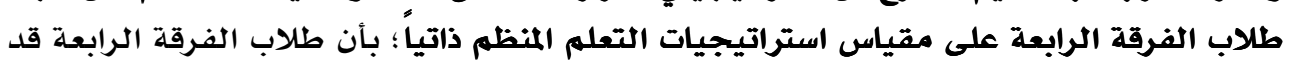

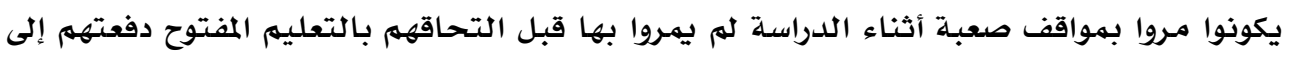

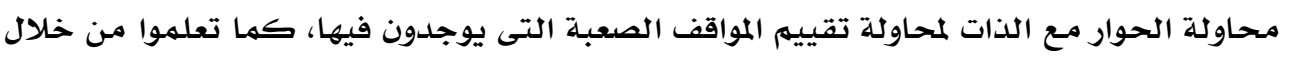


هذه المواقف الصعبة ضرورة تنشيط الأداء من خلال تكرار المواقف الصعبة مما زاد من استخدامهمه

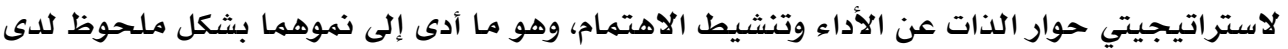

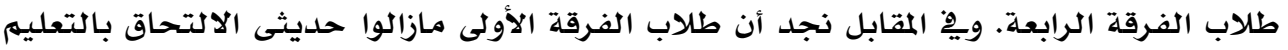

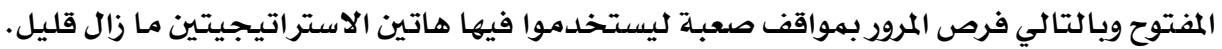

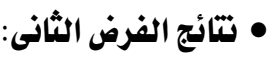

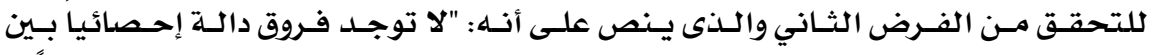

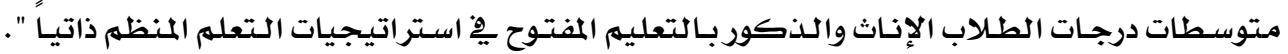

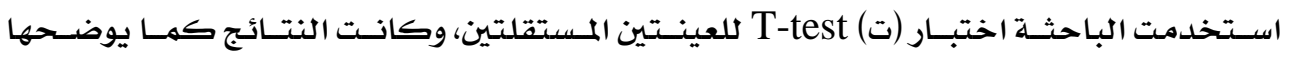

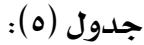

\section{جدول (0)}

قيمة (ت) ودلالتها للفروق بين متوسطات درجات الطلاب الإناث والذكور بالتعليم المفتوح على مقياسى (ه)

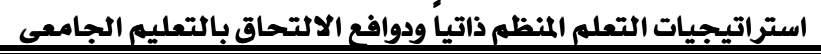

\begin{tabular}{|c|c|c|c|c|c|c|}
\hline \multirow[t]{2}{*}{ مستوى } & \multirow[t]{2}{*}{ قيمة (ت) } & \multicolumn{2}{|c|}{ 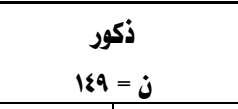 } & \multicolumn{2}{|c|}{ 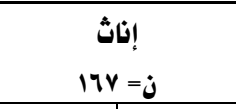 } & \multirow[t]{2}{*}{ البعد } \\
\hline & & $\varepsilon$ & $\hat{\imath}$ & $\varepsilon$ & p & \\
\hline \multicolumn{7}{|c|}{ استراتيجيات التعلم المنظم ذاتياً } \\
\hline غير دال & $1, r \mid \varepsilon$ & 1,990 & Ir, rro & $r, \cdot 7 r$ & Ir,ars & التسميع \\
\hline غير دال & $\cdot, \cdot \wedge \varepsilon$ & $1, V \leqslant \varepsilon$ & Ir, Y99 & 1,ov. & $|r, A| \xi$ & التفصيل \\
\hline$\cdot, \cdot 1$ & r, Trr & $r,\{\& Y$ & $1 \cdot, \vee \wedge 0$ & r, rav & $11,0 . r$ & التنظيم \\
\hline$\cdot, \cdot 0$ & r,IVa & $r, 10 r$ & 10, \&Ar & r,AYr & 17, rrr & المراقبة \\
\hline$\cdot, \cdot 0$ & 1,979 & $r, 7 r r$ & $11, \cdot 9 r$ & $r, 11 \varepsilon$ & $11,7 \cdot 0$ & التخطيط \\
\hline$\cdot, \cdot 0$ & $r, r \leqslant q$ & r,09r & $1 \cdot, 97$. & r, rro & $11,07 r$ & مكافأة الذات \\
\hline$\cdot, \cdot 1$ & $r, 007$ & r, ros & $1 \cdot, 7 \leq \varepsilon$ & $r, 179$ & 11,800 & الضبط البيئي الداففى \\
\hline 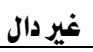 & •,rir & r, Iro & Ir, TIV & r,rar & Ir,Ar. & حوار الذات عن الكفاءة \\
\hline$\cdot, \cdot 0$ & r, rrr & $Y, 0.7$ & 11,190 & r,011 & $11, \wedge r \wedge$ & حوار الذات عن الأداء \\
\hline 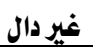 & 1,rrv & $r, \neg r \cdot$ & $\mathbb{I r}, \wedge \leqslant 7$ & $\curlyvee, \uparrow \cdots$ & $1 \varepsilon, r \varepsilon$. & تنشيط الاهتمام \\
\hline 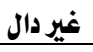 & $\cdot, 000$ & r,rir & $1 r, 1 \cdot v$ & r, $7 v\urcorner$ & Ir, rar & الضبط البيئي \\
\hline$\cdot, \cdot 1$ & $r, 717$ & $r,\{11$ & $1 \cdot$, ori & $r, \wedge 07$ & 11, ror & طلب العوز \\
\hline غير دال & $1, v+1$ & r, १r. & $\mid r, 711$ & $r, \neg r v$ & $1 \varepsilon, \mid r$. & تعلم الأقران \\
\hline غير دال & 1,100 & $r, \cdot \xi 1$ & 1.,Arr & $r, 7 \xi$. & $11,\{Y 0$ & البحث عن المملومات \\
\hline غير دال & $\cdot, 001$ & $r, \S 1 \Lambda$ & $11,10 \varepsilon$ & $r, r \cdot \varepsilon$ & $11, \cdots 4$ & الاحتفاظ بالسجلات \\
\hline غير دال & $\cdot, 071$ & $r, \eta \cdot \xi$ & Ir,O.r & $r, 0 \cdot r$ & 15,790 & إدارة الوقت \\
\hline$\cdot, \cdot 1$ & $r, 7 \cdot r$ & $r, 7 \Lambda$ & 11, rar & r,YIE & 11,998 & تقويم الذات \\
\hline
\end{tabular}


يتضح من جدول (0) ما يلى:

\section{فيما يتعلق باستراتيجيات التعلم المنظم ذاتياً:}

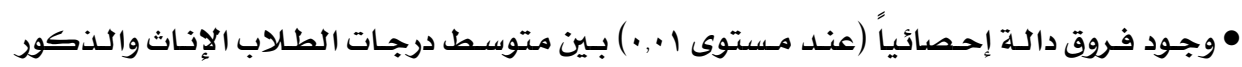

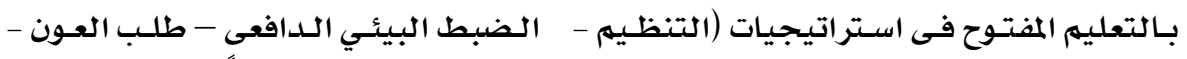

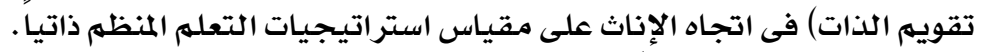

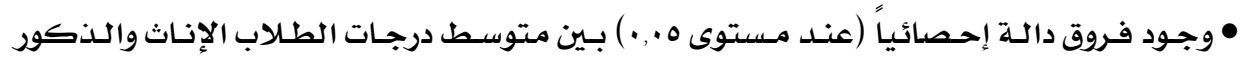

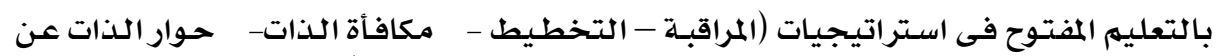

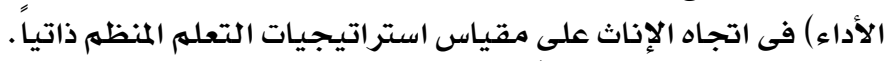

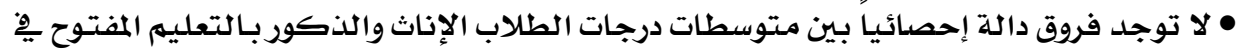

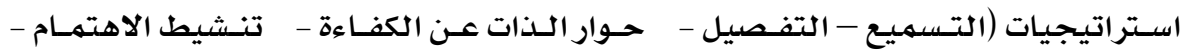

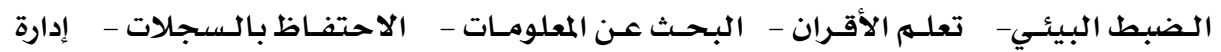
الوقت) على مقياس استراتيجيات التعلهم المنظم ذاتياً.

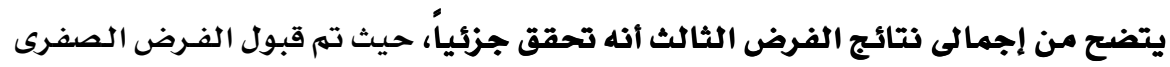

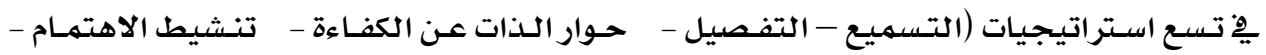

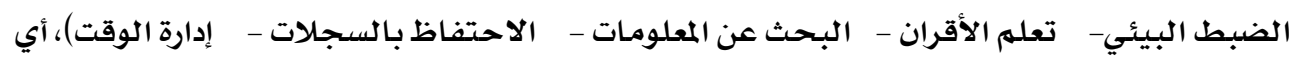
تم قبول الفرض الصفرى الثاني.

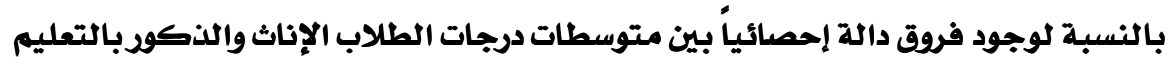

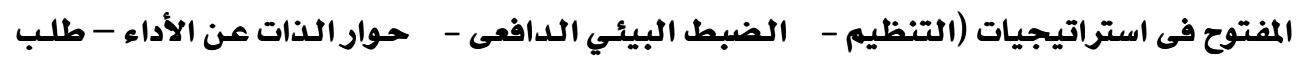

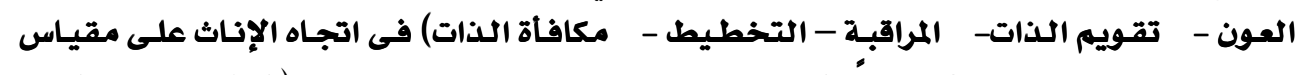

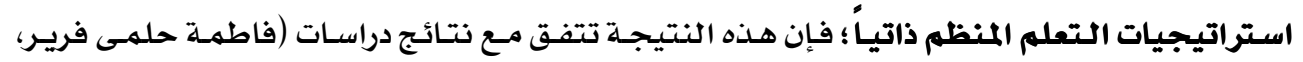

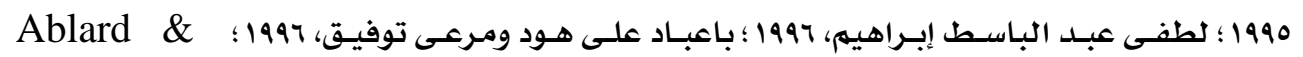

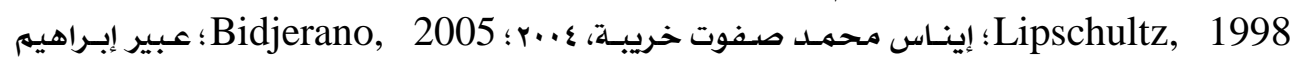

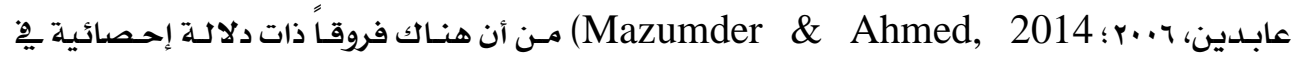
استراتيجيات التعلهم المنظم ذاتياً يِّات اتجاه الإناث.

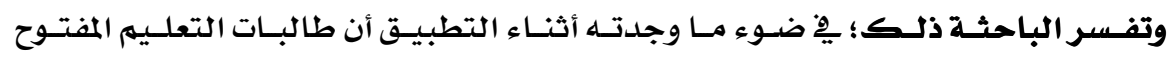

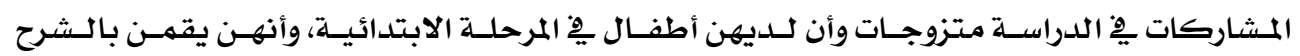

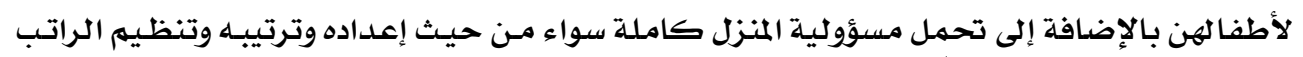

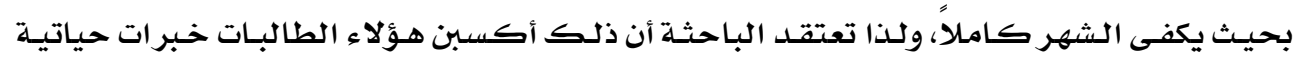

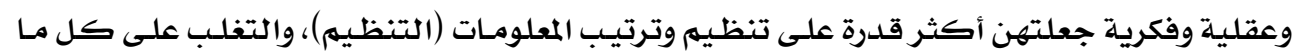

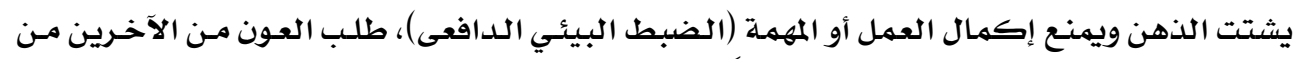

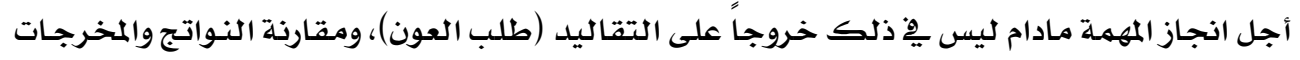

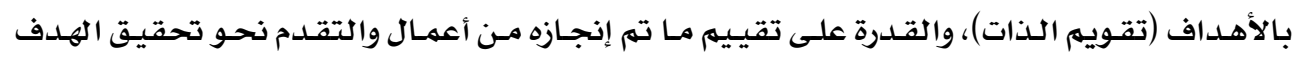




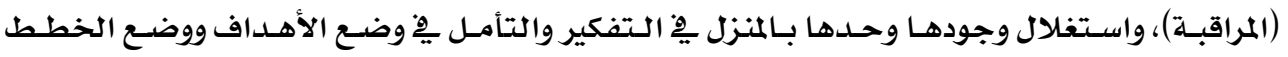

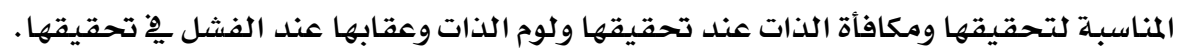

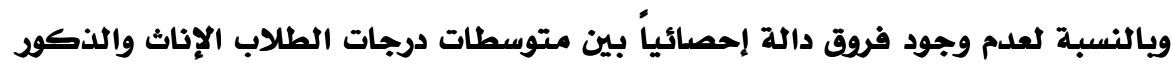

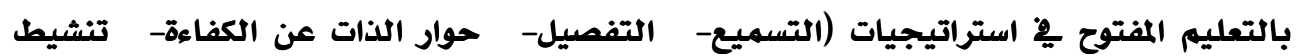

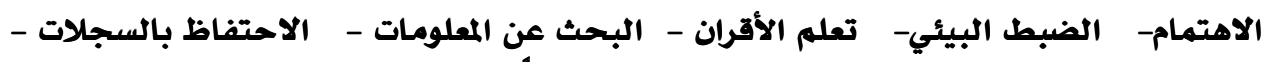

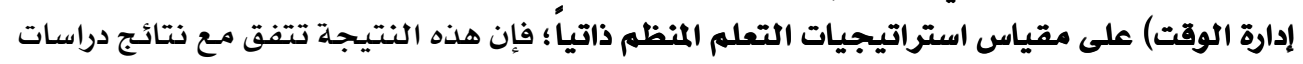

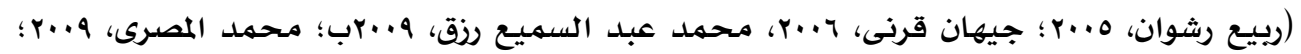
؛Balam, 2015 ؛Mazumder \& Ahmed, 2014 ؛Yukselturk \& Bulut, 2009 (Spahar, 2015 Mazumder \& Dakeev, 2015 الذكوروالإناث ِِّ استراتيجيات التعلهم المنظم ذاتياً.

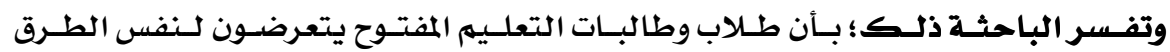

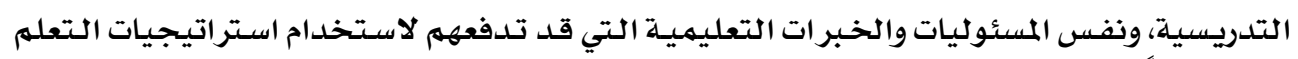

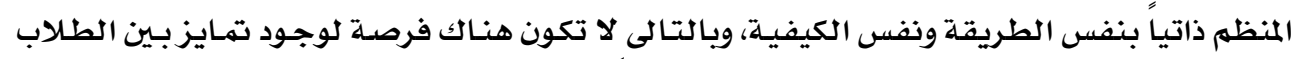

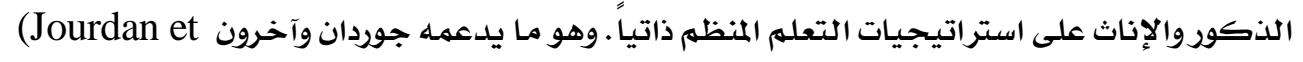

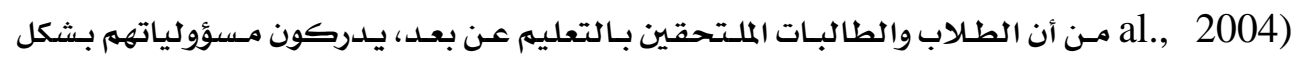

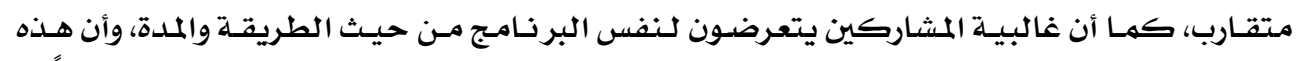

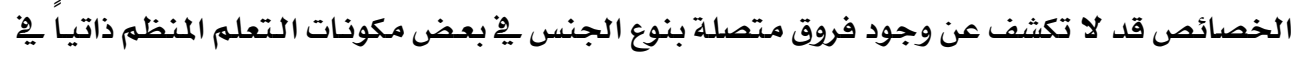
• برنامـج التعليهم عن بعد.

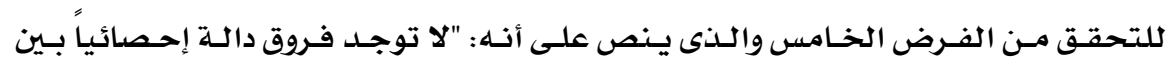

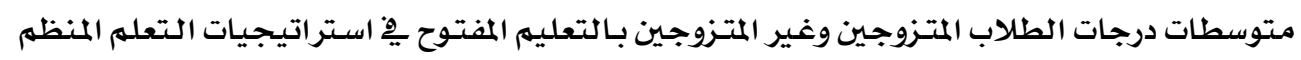

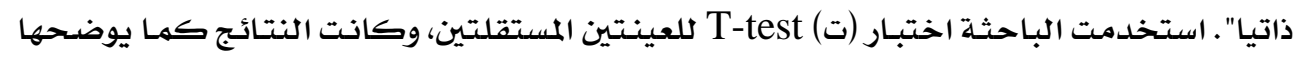
جدول (7): 


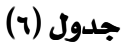

قيمة (ت) ودلالتها للفروق بين متوسطات درجات الطلاب المتزوجين وغير المتزوجين بالتعليم المفتوح على (هلى

مقياس استراتيجيات التعلم المنظم ذاتياً

\begin{tabular}{|c|c|c|c|c|c|c|}
\hline \multirow[t]{2}{*}{ مستوى } & \multirow[t]{2}{*}{ قيمة (ت) } & \multicolumn{2}{|c|}{ متزوج = مثاج } & \multicolumn{2}{|c|}{ غير متزوج } & \multirow[t]{2}{*}{ البعد } \\
\hline & & $\varepsilon$ & $\stackrel{2}{+}$ & $\varepsilon$ & $\stackrel{2}{p}$ & \\
\hline \multicolumn{7}{|c|}{ استراتيجيات التعلم المنظم ذاتياً } \\
\hline غير دال & $1,1 \cdot 1$ & $r, \cdot \xi \cdot$ & $\operatorname{Ir}, 9 \wedge \cdot$ & $r, \cdot r \cdot$ & IT, r£纟 & التسميع \\
\hline غير دال & $\cdot, 794$ & $1,70 \mathrm{r}$ & $1 Y, \wedge 07$ & $1,7 \leqslant V$ & Ir, Yrr & التفصيل \\
\hline غير دال & •, Vrr & r,ory & $11, r+q$ & r,Y৭ะ & $11, \cdot r 0$ & التنظيم \\
\hline غير دال & $\cdot, 9 \leqslant 9$ & $r, \cdot r r$ & $10, \mathrm{YOI}$ & $r, \cdot r l$ & $17, \cdot 1 r$ & المراقبة \\
\hline غير دال & •,oor & $r,\{r \mid$ & $11, \xi \cdot \wedge$ & r,rAs & II, ror & التخطيط \\
\hline غير دال & $1, \cdots \varepsilon$ & r, ¿AY & $11, r q r$ & r,rra & $11, \cdot v \wedge$ & مكافأة الذات \\
\hline غير دال & 1,rr. & r,rrA & $1 \cdot, 177$ & r,orr & 11, sto & الضبط البيئي الدافىى \\
\hline غير دال & -, ora & r,orr & Ir, I7v & r,OrA & Ir,AYY & حوار الذات عن الكفاءة \\
\hline غير دال & $1,\{91$ & $r, Y \wedge r$ & $11,7 \wedge \vee$ & $r, r$. & $11, r v$. & حوار الذات عن الأداء \\
\hline غير دال & $1, r i 1$ & 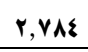 & 1E, YTE & $r, r r r$ & Ir,vra & تششيط الاهتمام \\
\hline غير دال & $\cdot, 71$ & r,arr & $1 r, 1 r q$ & r,qrr & Ir,rra & الضبط البيئي \\
\hline غير دال & $\cdot, 7 \leqslant 7$ & r,OAD & $1 \cdot, 91$ & $r, \wedge \leqslant \eta$ & $11,11 r$ & طلب العوز \\
\hline غير دال & $\cdot, \wedge \wedge 0$ & r,ril & Ir, १A• & r,orq & $1 \%, v \cdot \varepsilon$ & تعلم الأقران \\
\hline غير دال & $\cdot, 0 \wedge 0$ & $r, \wedge \leqslant r$ & $11, \cdot$ Yo & $r, \wedge 7 r$ & $11, r v$. & البحث عن المعلومات \\
\hline غير دال & •, ror & $r, \& \& Y$ & $11, \cdots$ & $r, 19$. & $11, r \cdot q$ & الاحتفاظ بالسجلات \\
\hline غير دال & $\cdot, \mathrm{Y} 19$ & $r,\{\wedge \mid$ & Ir, I7v & r, IVr & Ir, §OY & إدارة الوقت \\
\hline غير دال & $\cdot, 17 r$ & r,ova & 11,798 & r,§Ir & $11,71 \mathrm{~V}$ & تقويم الذات \\
\hline
\end{tabular}

يتضح من جدول (؟) ما يلى:

فيما يتعلق باستراتيجيات التعلم المنظم ذاتياً:

• لا توجد فروق دالة إحصائياً بين متوسطات درجـات الطلاب المتزوجين وغير المتزوجين بـالتعليم

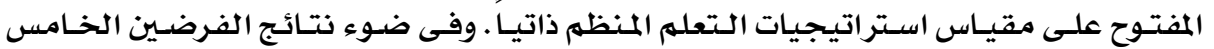

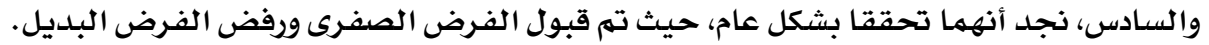

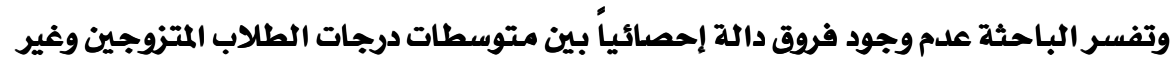

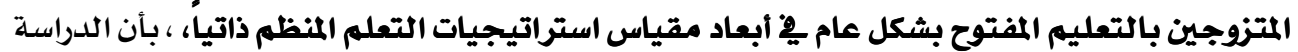

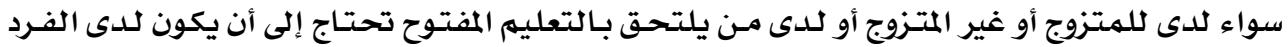

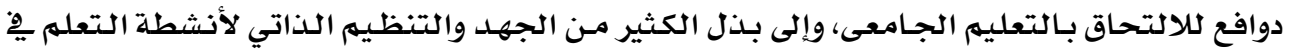

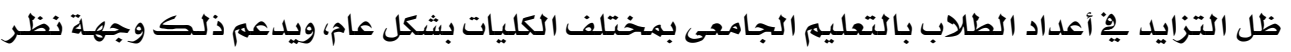


كل مـن شـانك (1996) Schunk وزيمرمـان (2002) Zimmerman بأن المتعلمـين لم يصبحوا

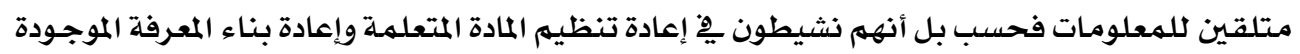

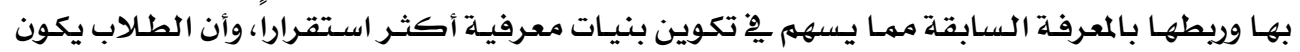

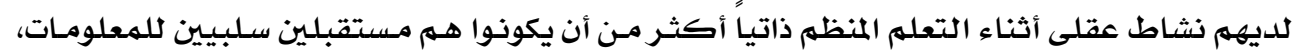

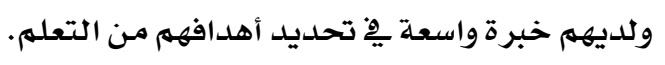

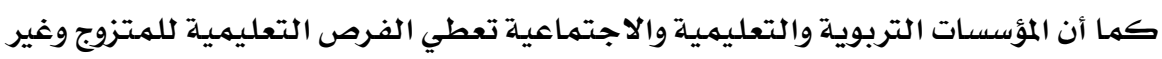

المتزوج على حد سواء دون تمييز، ويتعرضان لنفس الخبر ات التعليمية والتدريسية والتقويمية التهية.

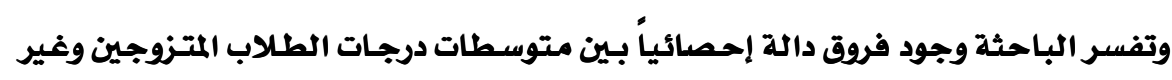

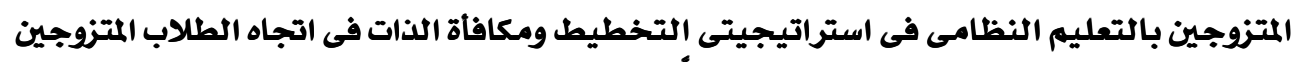

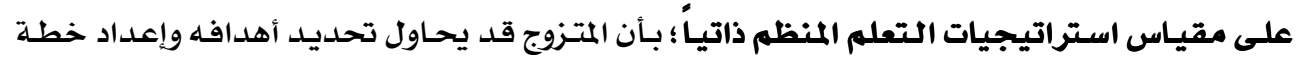

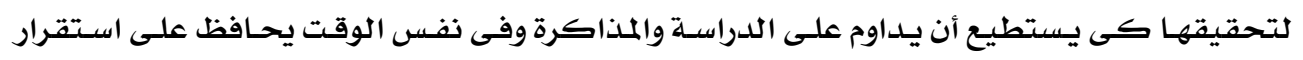

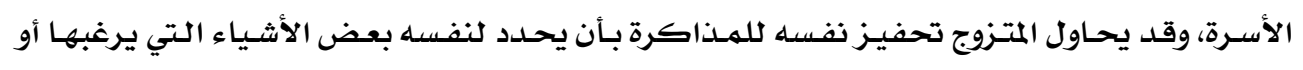

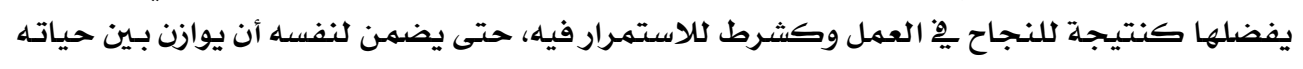
الأسرية وحياته الدراسية.

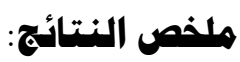

يمكن إيجاز نتائج الدراسـة الحالية وما أسفرت عنده فيما يأتي:

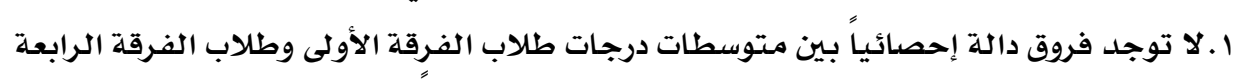

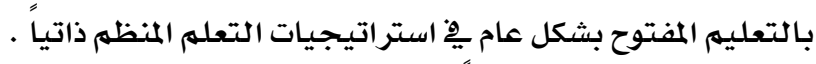

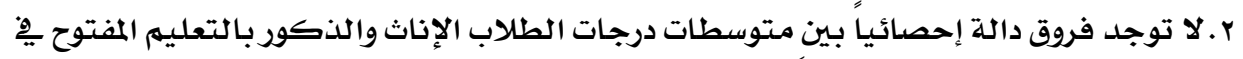

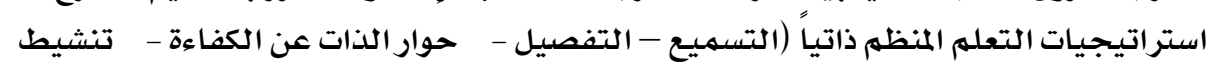

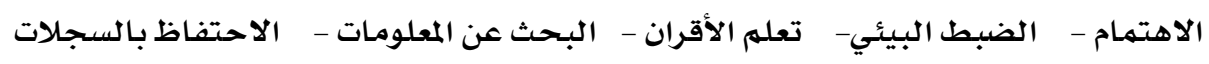

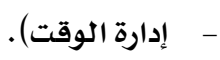

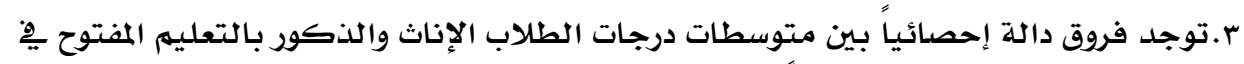

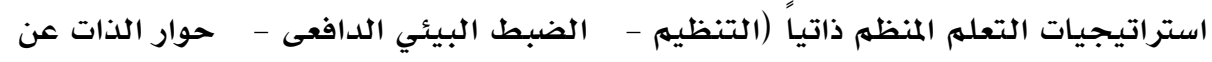

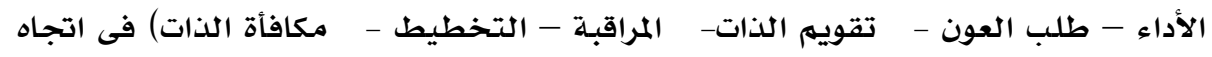

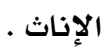
ع. لا توجد فروق دالة إحصائياً بين متوسطات درجات الطلاب المتزوجين وغير المتزوجين بالتعليم المفتوح يِّ استراتيجيات التعلم المنظم ذاتياً . 


\section{توصيات الدراسة:}

هِْ ضوء نتائج الدراسـة الحالية يمكن إبداء التوصيات التربوية التالية: توصي الدراسلة بضرورة تدريب الطلاب من خلال المناهج الدراسية المختلفة يْ جميع كليات

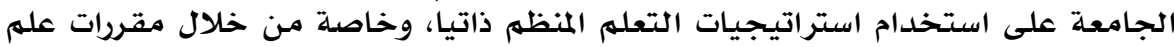

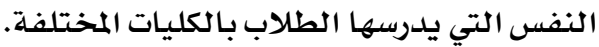

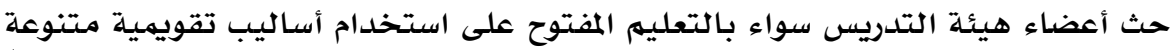

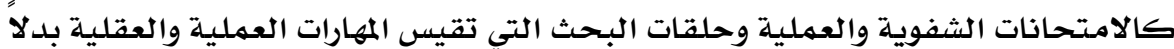

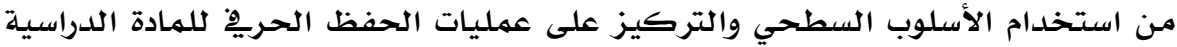

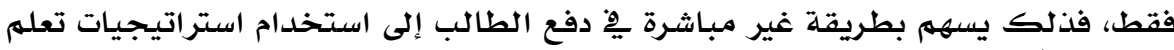

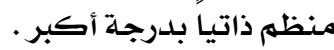

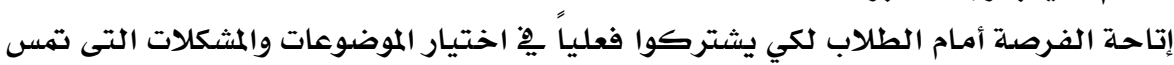

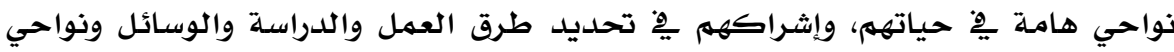
النشاط التي توصلهم إلى تحقيق دوافعهم التي يهلدفون إليها باستخدام استراتيجيات تعلهم مناسبـة. اشتراك الطلاب ِِّ أنشطة تعليمية يعتمدون فيها على استراتيجيات التعلهم المنظم ذاتياً مـع

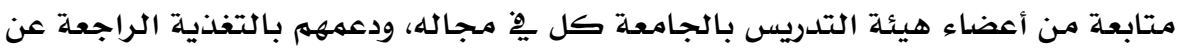

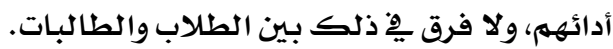
تحويل حجم أكبر من المسؤولية للطالب ومنحهـ سياق ومناخ غنى بالاتصالات الالكترونية بالمكتبة الجامعية، لمساعدته ِِّ تحديد أهدافه، وتطوير التفكير الذاتي (التأملى)، وإعطاء

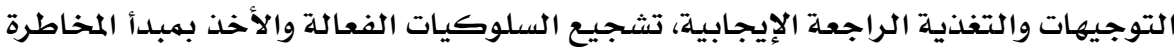

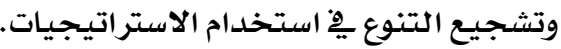

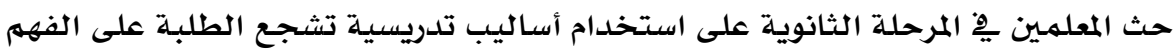

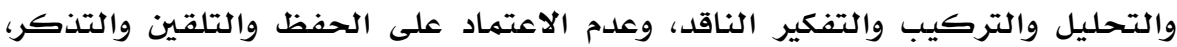

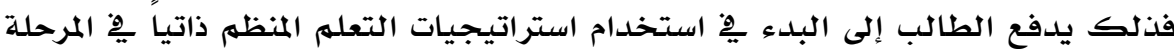

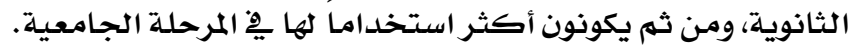

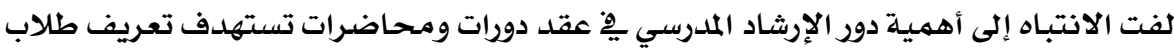

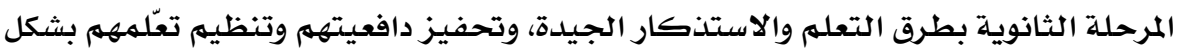
ذاتي من خلال الاستفادة من التصورات النظريـة الحديثة عن التعِّمى المنظّم ذاتياً.

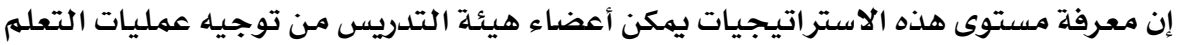

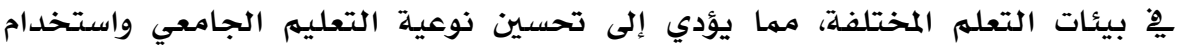
استراتيجيات تعليميلة متنوعة. 
- توجيه أعضاء هيئة التدريس لحث الطلبة على استخدام استراتيجيات التعلم ولاسيما

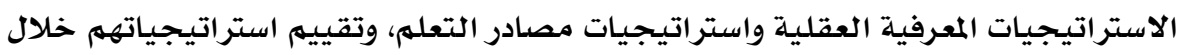

إنجاز المهمهات التعليمية.

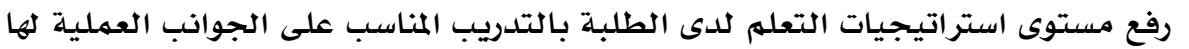
وعدم الاكتفاء بتقديه المعلومات النظرية لمقرر مهارات دراسية وبحثية.

بهوث ودراسات هقترحة

هِ ضوء نتائج الدراسـة الحالية تقترح الباحثة إجراء الدراسـات التالية:

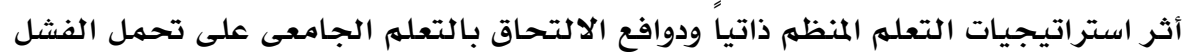

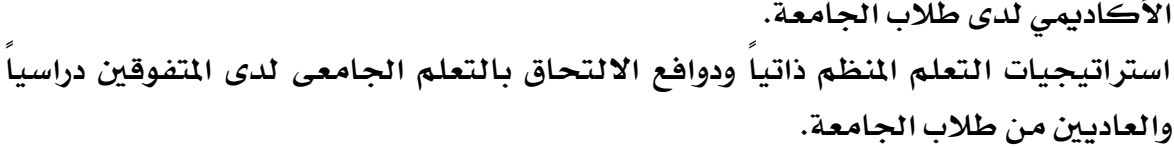

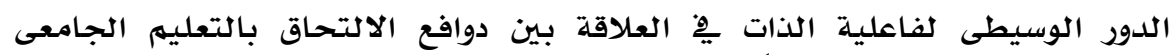

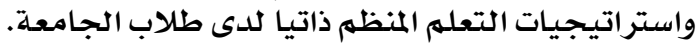

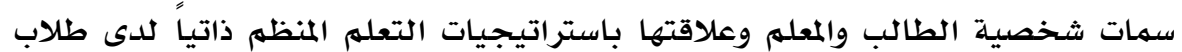

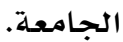

\section{المراجع العربية المرابة}

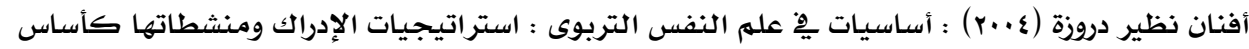

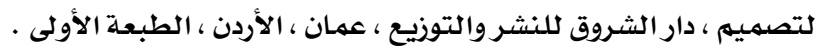

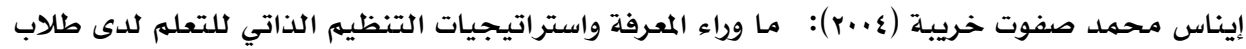
جامعة الزقازيق، ماجستير (غير منشورة )، كلية التربية، جامعة الزبة الزقازيق.

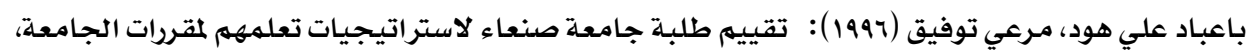

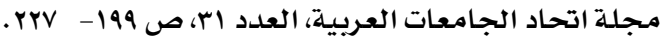

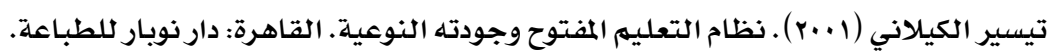

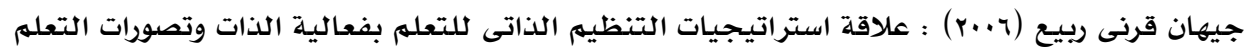

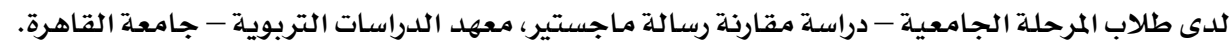

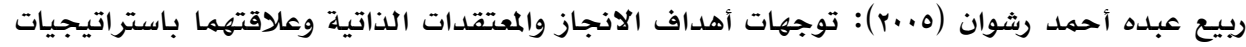

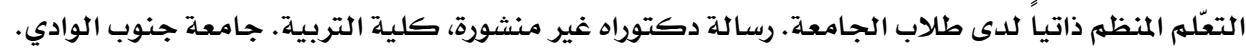
قنا. مصر. ربيع عبده أحمد رشوان (؟... (ب): التعلهم المنظم ذاتيا وتوجهات أهداف الإنجاز: نماذج ودراسات معاصرة.

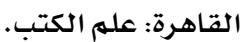




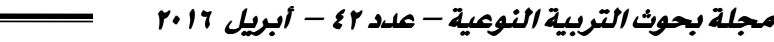

صلاح أحمد مراد (.... ) : الأساليب الاحصائية يج العلوم النفسية والتربوية والاجتماعية ، القاهرة، مكتبة

الأنجلو المصرية.

عبير ابراهيم عابدين (ج. (r): استراتيجيات التعلالمنظم ذاتيا، رسالة ماجستير، جامعة المنوفية ، كلية

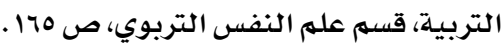

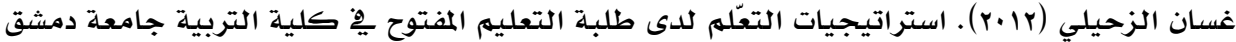

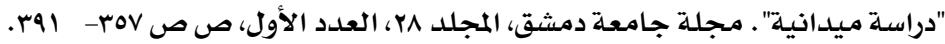

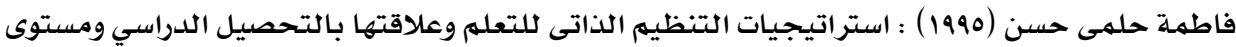

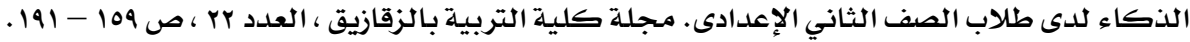

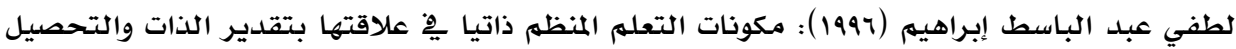

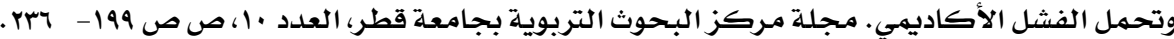

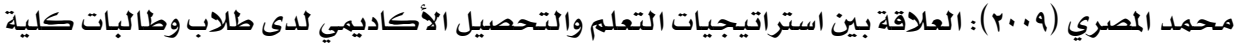

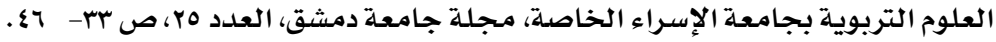

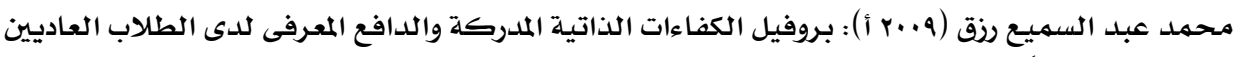

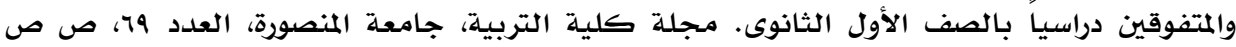
$.179-1199$

محمد عبد السميع رزق (q. . ب ب): استراتيجيات التعلهم المنظم ذاتياً وفاعلية الذات لدى المتفوقين دراسيا

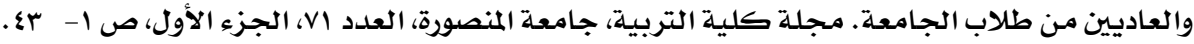

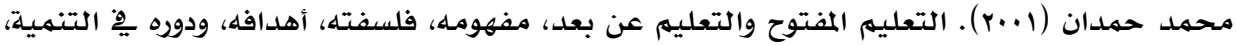

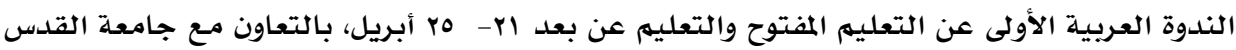

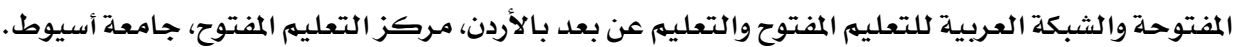

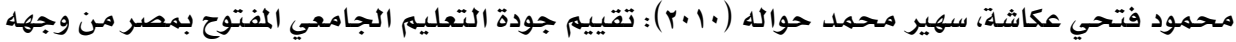

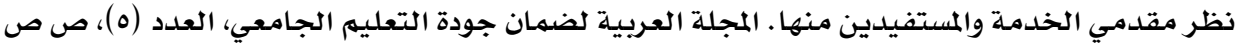
. $20-1$

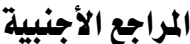

- Ablard, K. \& Lipschultz, R. (1998) : Self-regulated learning in high- achieving students : relations to advanced reasoning, achievement goals, and gender. Journal of Educational Psychology, 90, 1, Pp.94-101.

- Austin, D. B. (2005). The effects of a strengths development intervention program upon the self-perceptions of students ' academic abilities. Dissertation Abstracts International: Section A, 66, 1631-1772.

- Bidjerano, T. (2005). Gender differences in self-regulated learning. Paper presented at the Annual Meeting of the Northeastern Educational Research Association, October 19-21, Kerhonkson, NY, USA. 
- Braten, I., \& Stromso, H. I. (2005). The rekationship between epistemological beliefs, implicit theories of intelligence, and self-regulated among Norwegian postsecondary students. British Journal of Educational Psychology, 75, 539565.

- Bulter, A., Phillman, K., \& Smart, L. (2001). Active learning with a lecture: Assessing the impact of short, in-class writing exercises. Teaching of Psychology, 28(4), 257-259.

- Cheng, E. (2011). The role of self-regulated learning in enhancing learning performance. The International Journal of Research and Review, 6(1), 1-16.

- Harlow, L. L., Burkholder, G. J., \& Morrow, J. A. (2002). Evaluating attitudes, skill, and performance in a learning enhanced quantitative methods course: A structural modeling approach. Structural Equation Model, 9(3), 413-430.

- Hiemstra, D., \& Van Yperen, N. W. (2015). The effects of strength-based versus deficit-based self-regulated learning strategies on students " effort intentions. Motiv Emot, 39, 656-668

- Jacobson, R. R., \& Harris, M. S. (2008). Does the type of campus influence self-regulated learning a measured by the motivated strategies for learning questionnaire (MSLQ). Institute of Educational Sciences; 128, 412-431.

- Jourdan, L. F., Bagwell, J. J., \& Crawford, G. W. (2004): Motivational Orientation, Self-Regulated Learning Strategies and Students' Choice of Teaching Model. Academy of Educational Leadership Journal, 8(1).

- Balam, E. M. (2015): Learning Strategies and Motivation of Graduate Students: Is Gender a Factor?. Institute for Learning Styles Journal, 1, 1-9.

- Linley, P., Nielsen, K. M., Gillett, R., \& Biswas-Diener, R. (2010). Using signature strengths in pursuit of goals: Effects on goal progress, need satisfaction, and well-being, and implications for coaching psychologists. International Coaching Psychology Review, 5,

- Mazumder, Q. H., \& Ahmed, K. (2014). A Comparative Study of Motivation and Learning Strategies between Public and Private University Students of Bangladesh. Proceedings of the 2014 ASEE North Central Section Conference, April 4-5, 2014, Oakland University, USA. 
- Mazumder, Q. H., \& Dakeev, U. (2015). A Comparative Study of Motivation and Learning Strategies between High School and University Students. Paper presented at 2015 ASEE Annual Conference and Exposition, Seattle, Washington.

- Mullen. P. (2007). Use of Self-Regulating Learning Strategies by Students in the Second and Third Trimesters of an Accelerated Second-Degree Baccalaureate Nursing Program. Journal of Nursing Education, 46(9), 406

- Narciss, S. (2007). Promoting self-regulated learning in web-based learning environments. Computers in Human Behavior, 23(3), 1126-1144.

- Parsad, B. \& Lewis, L. (2008). Distance Education at Degree-Granting Postsecondary Institutions: 2006-07 (NCES 2009-044). National Center for Education Statistics, Institute of Education Sciences, Washington, DC.

- Paulsen, M. \& Gentry, J. (1995). Motivation, learning strategies, and academic performance: A study of the college finance classroom. Financial Practice $\&$ Education, 5(1), 78-89.

- Proctor, C., Maltby, J., \& Linley, P. (2011). Strengths use as a predictor of wellbeing and health-related quality of life. Journal of Happiness Studies, 12, 153-169.

- Quible, Z. (2006). Analysis of the Motivational Orientation of and Learning Strategies used by Students in a Written Business Communication Course. Delta Pi Epsilon Journal, 48(3), 168-190.

- Ringsted C. matte (1998), open learning in primary and secondary school. Towards the school of tomorrow in the information society, Education media international, vol 35, Ny.

- Ryan, R. M., \& Deci, E. L. (2000). Self-determination theory and the facilitation of intrinsic motivation, social development, and wellbeing. American Psychologist, 55, 68-78.

- Samms, C. L., \& Friedel, C. R. (2012). Relationship between Dissimilar Cognitive Styles and Use of Learning Strategies in Undergraduate Students. Academy of Educational Leadership Journal, 113-130, Education Full Text (H.W. Wilson). 
- Spahr, M. L. (2015). Gender, Instructional Method, and Graduate Social Science Students' Motivation and Learning Strategies. Doctoral dissertation, College of Social and Behavioral Sciences, Walden University.

- Steffens, K. (2006). Self-regulated learning in technology-enhanced learning environments: Lessons of a European peer review. European Journal of Education, 41(3), 353-380.

- Vrugt, A., \& Oort, F. J. (2008). Metacognition, achievement goals, study strategies and academic achievement: Pathways to achievement. Metacognition Learning, 30, 123-146.

- Wabberley, R., \& Haffenden, I. (1987). Skills training and responsive management. In M. Thorpe \& D. Grugeon, (Eds.), Open Learning for Adults. (p. 137-146). Harlow: Longman.

- Wang, Y., Peng, H., Huang, R., Hou, Y., \& Wang, J. (2008). Characteristics of distance learners: Research on relationships of learning motivation, learning strategy, self-efficacy, attribution and learning results. Open Learning: The Journal of Open and Distance Learning, 23(1), 17-28.

- Yukselturk, E., \& Bulut, S. (2009). Gender Differences in Self-Regulated Online Learning Environment. Educational Technology \& Society, 12 (3), $12-22$.

- Zimmerman, B. J. (2002). Becoming a self-regulated learner: An Overview. Theory into Practice, 41(2), 64-70.

- Zumbrunn, S., Tadlock, J., \& Roberts, E. (2011). Encouraging self-regulated learning in the classroom: A review of the literature. Metropolitan Educational Research Consortium (MERC), Virginia Commonwealth University. 


\section{Study summary:}

The current study aims to identify the self-organized learning strategies, the open education students have Demographic in light of some variables (Grade - Kind - Social - Status) where the sample consisted of 316 students from the open learning students at Mansoura university, where they were chosen from three faculties.

$$
\text { (Arts - Law - Commerce) }
$$

From the first Grade and the fourth Grade that Making the students better able to watch their self organized strategies and with the using of the scale of-organized learning strategies

(prepared by/ Rabi Abdu Ahmed 2005)

And with the using of the test "T" The Results Pointed that there are no statistically significant differences among the averages of the first Grade and the fourth Grade in the open learning student's degrees generally in the self-organized learning strategies. 